\title{
Algunas reflexiones sobre la representación del tiempo en la imaginería maya antigua
}

Some thoughts on the representation of time in Classic Maya imagery Quelques réflexions sur la représentation du temps dans l'imagerie maya classique

\section{Erik Velásquez García}

\section{CpenEdition}

\section{Journals}

Edición electrónica

URL: http://journals.openedition.org/jsa/15502

DOI: $10.4000 /$ jsa. 15502

ISSN: 1957-7842

Editor

Société des américanistes

Referencia electrónica

Erik Velásquez García, « Algunas reflexiones sobre la representación del tiempo en la imaginería maya antigua », Journal de la Société des américanistes [En línea], Maya times | 2017, Publicado el 31 diciembre 2017, consultado el 10 diciembre 2020. URL : http://journals.openedition.org/jsa/15502 ; DOI : https://doi.org/10.4000/jsa.15502 


\title{
Algunas reflexiones sobre la representación del tiempo en la imaginería maya antigua
}

\author{
Erik VelásQuez GaRCÍA*
}

Este trabajo enuncia y explora algunas de las muchas estrategias que los artistas mayas del periodo clásico (250-900 d.C.) utilizaron para representar o sugerir el flujo del tiempo: la contención de volúmenes escultóricos, la manipulación de las fechas, la distribución convencional de las figuras en el campo pictórico, la yuxtaposición de distintos tiempos y espacios, el ángulo simultáneo de visión, el desplazamiento entre causas (indicadas en los textos) y sus efectos (representadas en las imágenes), la secuencia in praesentia, la secuencia in absentia y la peripéteia o instante elocuente que sugiere psicológicamente la sensación de cambio o viraje. El común denominador de todos estos recursos es la unión íntima entre tiempo y espacio, como dos aspectos de la misma realidad, donde el flujo narrativo implica la idea de secuencia cronológica, pero también de ordenamiento espacial. [Palabras claves: artes visuales, tiempo-espacio, retórica de las imágenes, flujo narrativo, instante elocuente.]

Some thoughts on the representation of time in Classic Maya imagery. This work registers and explores some of the many strategies that Mayan artists of the Classic period (AD 250-900) used to represent or suggest the flow of time: the containment of sculptural volumes, the manipulation of dates, the conventional distribution of figures in the pictorial field, the juxtaposition of different times and spaces, the simultaneous angles of view, the displacement between causes (indicated in the texts) and their effects (represented in the images), the sequence in praesentia, the sequence in absentia, and the peripeteia or eloquent instant that suggests psychologically the feeling of change or turning. The common denominator of all these means is the intimate union between time and space, as two aspects of the same reality, where the narrative flow implies the idea of chronological sequence, but also of spatial ordering. [Key words: visual arts, time-space, rhetoric of images, narrative flow, eloquent instant.]

Quelques réflexions sur la représentation du temps dans l'imagerie maya classique. Ce travail répertorie et explore certaines des nombreuses stratégies mises

* Instituto de Investigaciones Estéticas, Universidad Nacional Autónoma de México [inkabaeeric@gmail.com]. 
en œuvre par les artistes mayas de la période classique (250-900 apr. J.-C.) pour représenter ou suggérer le flux du temps: l'hiératisme (ou non) des sculptures, la manipulation des dates, la distribution conventionnelle des figures dans le champ pictural, la juxtaposition de temps et d'espaces distincts, les angles de vue simultanés, le déplacement entre les causes (indiquées dans le texte) et leurs effets (représentés par les images), la séquence in praesentia, la séquence in absentia, et la peripeteia, soit l'instant éloquent qui suggère, d'un point de vue psychologique, une sensation de changement ou un tournant. Le dénominateur commun de l'ensemble de ces moyens est l'union intime entre le temps et l'espace, conçus comme deux facettes d'une même réalité, au sein de laquelle le flux narratif implique l'idée de séquence chronologique, mais également de mise en ordre spatiale. [Mots-clés : arts visuels, temps-espace, rhétorique des images, flux narratif, instant éloquent.]

Un lugar común es considerar los textos escritos como mensajes que se decodifican de forma lineal, en el tiempo, pues obedecen a un orden de lectura donde los elementos gráficos se encuentran unos detrás de otros. De acuerdo con ese punto de vista, los textos pictóricos (que incluyen tanto las representaciones icónicas o figurativas, como las geométricas, abstractas o no referenciales) ${ }^{1}$, al transmitir información de naturaleza no verbal, supuestamente presentan sus elementos gráficos de forma simultánea e inmediata, mediante un solo "golpe de vista", sin ninguna indicación evidente que prescriba el orden temporal en que deben ser mirados. No obstante, conviene decir que esta aparente dicotomía entre artes del tiempo y artes del espacio, entre signos escritos y signos iconográficos, es en realidad un espejismo, pues los textos escritos también ocupan un lugar en el espacio, mientras que el tiempo en las pinturas o esculturas subyace en el recorrido de la mirada, ya que el espectador necesita tiempo para captar los elementos de una escena y ponerla mentalmente en orden. Es decir, es solamente en el tiempo que el ojo humano recorre las distintas zonas de una composición pictórica, pues ni su mirada ni su cerebro son capaces de asimilarlo todo de un solo "golpe", si bien el orden en el que percibe un cuadro, una vasija, una viñeta, etcétera, es discontinuo o aleatorio, pues a diferencia de lo que suele ocurrir con una frase escrita sufre detenciones, vacilaciones y vueltas hacia atrás, en cualquier tipo de circuito de la vista (vid. Carrere González y Saborit Viguer 2000, p. 60-61, 114-118). Tanto en la escritura como en la pintura, el espectador reconstruye el mensaje relacionando distintos elementos que se encuentran simultáneamente en la imagen, ya sea logogramas, fonogramas,

1. Alberto Carrere González y José Saborit Viguer (2000, p. 127) definen el concepto de texto pictórico como "un conjunto de signos plásticos [color, forma y textura] e icónicos [figurativos] seleccionados de un repertorio inconcluso, cuya organización queda fijada por técnicas materiales en el que es posible realizar significados más o menos completos, autónomos y coherentes". 
determinativos semánticos, diacríticos o signos auxiliares en el caso de un texto escrito, o elementos plásticos e icónicos en el caso de un texto pictórico.

Las concepciones del tiempo constituyen un tema añejo en la investigación mayista, que, por lo menos, data de 1864, cuando Charles Étienne Brasseur de Bourbourg publicó la Relación de las cosas de Yucatán de fray Diego de Landa (1864), y gracias a ella pudo identificar los jeroglíficos de los días y de los meses en los códices (vid. Ayala Falcón 1985, p. 16-17; Coe 2010, p. 99-107). Eminentes investigadores se han ocupado del estudio de diversos aspectos y problemas del calendario maya, y hoy día contamos con renovadas miradas que, desde la lingüística, revaloran las fechas escritas en las inscripciones bajo la perspectiva de que cumplen la función sintáctica de adverbios, pues en los idiomas mayances los semas temporales sólo se encuentran en las fechas, adverbios de tiempo y en el contexto (Sanz González 2001, p. 69; 2003, p. 125; Lacadena García-Gallo 2010, p. 14). No obstante, existen pocos esfuerzos sistemáticos por abordar la representación del devenir en la iconografía o imaginería no verbal del arte maya.

Uno de ellos fue emprendido por Beatriz de la Fuente (2004, p. 56-60, 62-66), quien caracterizó las diferencias entre la escultura del Clásico Temprano y la del Tardío como dos posturas asumidas por el hombre maya frente a las categorías de tiempo y espacio. Por una parte, las imágenes estáticas, solemnes, hieráticas y autocontenidas que abundan en el Clásico Temprano ${ }^{2}$, revelan una realidad donde el espacio se ha cerrado para capturar el tiempo; implican una percepción distante, en el más allá, en la atemporalidad del espacio indefinido del anecúmeno o ámbito sagrado, que trasciende la percepción humana ${ }^{3}$. Por el contrario, el arte vitalista, narrativo y con tema humano del Clásico Tardío refleja un firme anclaje en el tiempo y el espacio, lo que se traduce en una particular conciencia del ecúmeno o ámbito mundano de las criaturas, sujeto a la percepción sensorial.

Más recientemente, Dmitri Beliaev ${ }^{4}$ notó que en muchas culturas "arcaicas" es importante la noción del "tiempo mítico" como parte de la explicación sobre

2. En la escultura temprana de Tikal, Uaxactún u otros sitios de las tierras bajas centrales, y que hasta cierto punto continúan durante el Clásico Tardío en el arte escultórico de Copán, Quiriguá y Toniná.

3. Comparto con Alfredo López Austin el punto de vista de que la diada "naturaleza" versus "sobrenaturaleza" no expresa cabalmente el punto de vista de la cosmovisión mesoamericana. Por ello sigo la propuesta de sustituirla por la de "ecúmeno" (ámbito de las criaturas finitas y lábiles) y "anecúmeno" (la otra región del universo, donde se cree que habitan los dioses, ancestros y otras fuerzas anímicas) (vid. López Austin y López Luján 2009, p. 43-50, 163 166; López Austin 2015a, 2015b, 2016, p. 79-80).

4. "El tiempo histórico y el tiempo mítico en las narraciones mayas clásicas", ponencia presentada en el marco de la VII Mesa Redonda de Palenque. Los mayas y las concepciones del tiempo, Palenque, Chiapas, México, 29 de noviembre de 2011. 
el origen del mundo y los rituales. Dicha noción remite a momentos ambiguos o imprecisos, pues pertenece a los mismos ámbitos de las experiencias oníricas que, paradójicamente, escapan a cualquier medición y por lo tanto son una especie de "pre-tiempo". Bajo esta perspectiva, Beliaev (2011) observa que los mayas antiguos se comportan como una cultura muy extraña, en virtud de que sus narrativas mitológicas tienen fechas precisas, lo que constituye un aparente contrasentido en relación a varios otros pueblos, para quienes los acontecimientos de esa naturaleza no se pueden fechar. Ello remarca la condición de que para los mayas no hubo una diferencia sustantiva entre el tiempo profano y el tiempo sagrado, pues los acontecimientos de los hombres y de los dioses se ubican en el mismo continuum temporal de la Cuenta Larga, si bien los ancestros míticos y héroes culturales se diferenciaban de los gobernantes "ordinarios" en que estos últimos usaban como nombres frases nominales derivadas de dioses, animales, "objetos" o papeles sociales, mientras que los primeros regularmente aluden a símbolos básicos e institucionales del poder o del ritual (Carter 2015, p. 11). Además, solían vivir más que los humanos, como ocurre con el paradigmático y legendario Ajaw "Foliado" o K'ihnich Yajawte' Uhx Yop Hu'n', quien supuestamente vivió al menos 295 años (Grube 2004, p. 127-131; Velásquez García 2011b, p. 408-410; Stuart 2014).

No obstante, Beliaev aventura la sospecha de que, al menos en algunas épocas y regiones restringidas, los artistas mayas idearon una convención para señalar el tiempo mítico, produciendo escenas cuyas fechas son incongruentes o imposibles desde el punto de vista de la mecánica del calendario. Tal es el caso de varios episodios mitológicos plasmados en las vasijas estilo códice (Figura 1), que

5. Sigo en este trabajo las convenciones ortográficas propuestas por Lacadena García-Gallo y Wichmann (2004), incluso en los gramemas o afijos de carácter morfológico (Lacadena García-Gallo y Wichmann s.f.), tales como - u'l en el caso de Kanu'l o Kaanu'l. Siguiendo con una idea formulada por Wichmann (2004, p. 80-81), en el sentido de que la palabra $k$ 'ihnich procede del sustantivo $k$ 'ihn, 'calor' o 'ira' y no de $k$ 'in, 'sol' o 'día', he desarrollado más la tesis de que los gobernantes mayas tenían una mayor concentración de esa cualidad o fuerza calorífica, misma que se acentuaba con la edad (Velásquez García 2009b, p. 543-552; 2015b, p. 186-187; s.f.a; s.f.b). Considero que cuando esa palabra precede los nombres propios de los mandatarios mayas, como en K'ihnich Janaab' Pakal, procede de k'ihn, mientras que cuando los sucede, como ocurre por ejemplo con Yajawte' K'inich, proviene de $k$ 'in. En ambos casos el sufijo $-V_{1}$ ch es un adjetivizador o nominalizador (Alfonso Lacadena García-Gallo, comunicación personal, 4 de julio de 2007). De igual modo considero plausible que en la lengua cholana de las inscripciones el nombre del número 3 haya sido $u h x$, toda vez que su reflejo en maya yucateco es óox, misma circunstancia que ocurre con otros vocablos como ihch'aak, 'garra', o yahx, 'primero', cuyos reflejos en yucateco respectivamente son iich 'ak y yáax. La lectura completa del nombre de Ajaw "Foliado" como K'ihnich Yajawte' Uhx Yop Hu'n es obra de Erik Boot (comunicación personal, 18 de octubre de 2016). 
Algunas reflexiones sobre la representación del tiempo

fueron producidas en el norte de Petén y sur de Campeche entre 672 y 751 d.C. Un atributo de dichas imágenes es que las fechas jeroglíficas que las acompañan violentan la correspondencia aritmética que debe existir entre el día del calendario adivinatorio de 260 (tzolk'iin) y el numeral del calendario solar de 365 días ( $h a^{\prime} a b$ '). Nikolai Grube (2004, p. 125) fue quizá el primer autor en percatarse de este fenómeno, mismo que interpretó como marcas de carácter simbólico y no como fechas auténticas. Beliaev piensa que este recurso de alterar las fechas pudo haber sido una estrategia deliberada para marcar que la escena tiene lugar en un tiempo distinto, de carácter numinoso, lo que, en cierto grado, encaja con el punto de vista de otros autores ${ }^{7}$, quienes opinan que en efecto se trata de fechas y no de meros elementos simbólicos. De hecho, Alfonso Lacadena García-Gallo ha encontrado indicios de la existencia de un sistema calendárico distinto, que precedió al que era usado durante el periodo clásico (apud García Barrios 2006, p. 113).

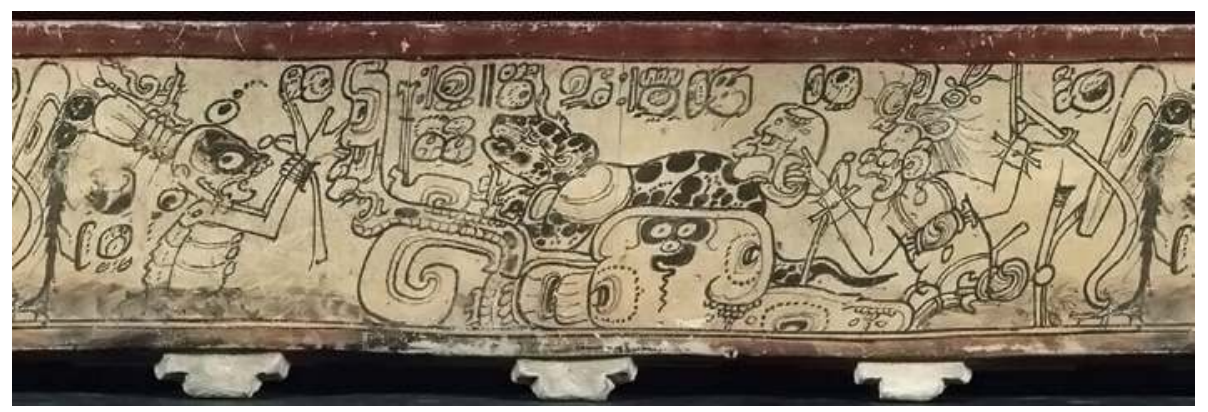

Fig. 1 - En diversas vasijas estilo códice, como la que se muestra aquí, las fechas que acompañan a las escenas míticas son imposibles desde el punto de vista aritmético, como es el caso de esta Rueda de Calendario $<7$ muluc $10 \mathrm{zac}>$, pues si el día del tzolk'iin es $\langle$ muluc $\rangle$, los únicos coeficientes posibles para $\langle z a c\rangle$ en teoría deben ser 2, 7, 12 y 17, jamás 10. Vaso K1152; fotografía y cortesía de Justin Kerr; tomada del archivo fotográfico de Kerr: http://research.mayavase.com/kerrmaya_hires.php?vase=1152.

6. En 1997 Dorie J. Reents-Budet, Simon Martin, Richard Hansen y Ronald L. Bishop fecharon las vasijas de estilo códice entre 672 y 731 d.C. (apud García-Barrios 2006, p. 129). Aunque tal vez sea más prudente considerar un k'atuun de duración más, llegando tentativamente hasta 751 d.C.

7. Stanley P. Guenter, "Gobernantes preclásicos en la Cuenca del Mirador", ponencia presentada en el marco del XVIII Simposio de Investigaciones Arqueológicas en Guatemala, Ciudad de Guatemala, Departamento de Guatemala, Guatemala, 22 de julio de 2004. Son de la misma opinión Juan Ignacio Cases Martín y Alfonso Lacadena García-Gallo (apud García Barrios 2006, p. 133). 
Otro ejemplo que puede citarse es el del llamado Vaso de la Serie Inicial (Figura 2) de la Estructura A-I de Uaxactún (vid. Smith 1955, vol. II, fig. 72b; Carter 2015; Boot 2016), que a primera vista contiene la imagen de una corte maya ordinaria del periodo Clásico Tardío (ca. 635-650), donde el gobernante entronizado es la figura principal.

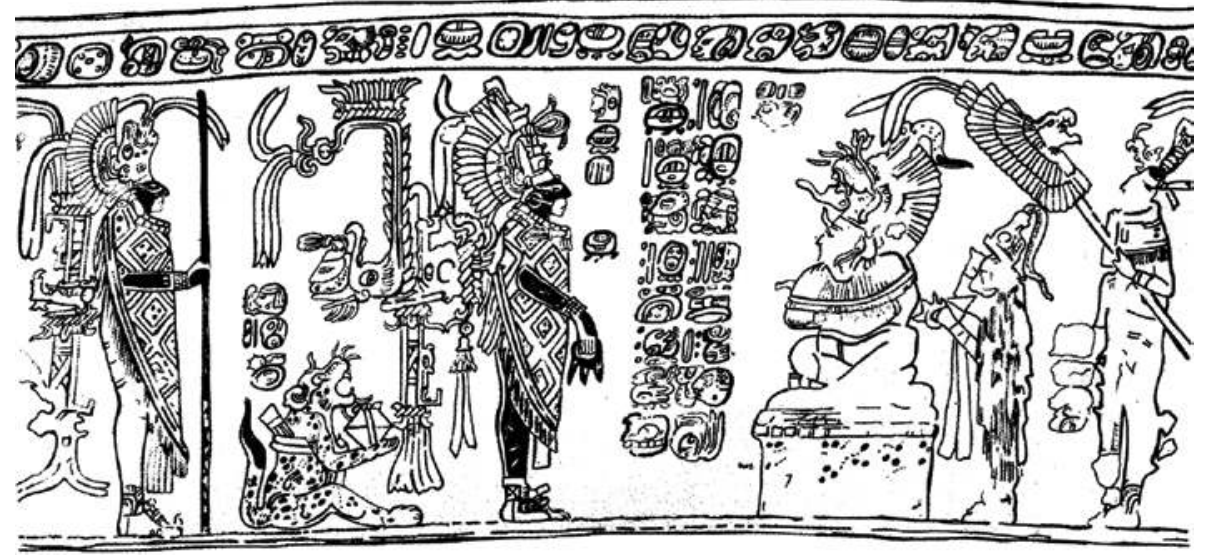

Fig. 2 - Vaso de la Serie Inicial de la Estructura A-I de Uaxactún; tomado de Grube y Martin (2001, II-13).

No obstante, la fecha de Cuenta Larga que acompaña a la escena se ubica en el año 256 a.C., mucho antes de las primeras dinastías mayas conocidas. Del mismo modo, esa Cuenta Larga debería conducirnos a una Rueda Calendárica $<13$ ahau 3 tzec $^{8}$, pero lo que está escrito es una fecha deliberadamente incorrecta: <8 ahau 13 kankin> (vid. Carter 2015, p. 5; Boot 2016, p. 2-3)9. Los recursos para marcar que el evento tiene lugar en el tiempo sagrado de los

8. Los corchetes angulares significan que respeto la ortografía maya tradicional, que procede de los tiempos novohispanos. En el caso de las fechas muchas veces es preferible usar los criterios de la época virreinal, en virtud de que desconocemos la longitud o naturaleza vocálica de los términos para los días y las veintenas, no sólo en maya yucateco sino aun en la lengua cholana de las inscripciones, donde aún existen días del tzolk'iin que no están descifrados. Tampoco existe una norma aceptada para el uso de mayúsculas en los vocablos calendáricos. Por tal motivo si escribo en castellano adopto el criterio de poner los nombres de los días y de los meses mayas con minúsculas, igual que se hace en español. Del mismo modo los escribo con cursivas o itálicas, en virtud de que se trata de palabras que están en idiomas distintos al castellano.

9. Nicholas P. Carter (2015) ha reunido la historiografía relacionada con el problema de esta fecha y ofrece una interpretación muy completa sobre este vaso y el contexto histórico donde fue producido en la primera mitad del siglo VII. 
ancestros no se acaban ahí. Antes bien, conviene llamar la atención sobre la pintura roja que sirve como fondo a la escena, cuyo pigmento plausiblemente derivó de la hematita $\left(\mathrm{Fe}_{2} \mathrm{O}_{3}\right)$, material telúrico y pesado, procedente del inframundo e indicador -según Alfredo López Austin (1989, vol. I, 70)- del "otro tiempo", el de los antepasados, pues de hecho se usaba para cubrir el cuerpo de los muertos ${ }^{10}$. Además debemos advertir que las imágenes, no obstante compartir las convenciones habituales para representar a los gobernantes mayas dentro de sus cámaras abovedadas (vid. Houston 1998), contienen detalles que parecen trascender lo intramundano o al menos lo profano. Entre ellos un felino destinado al sacrificio que sostiene una ofrenda dedicatoria o mortuoria (Carter 2015, p. 4) y la pintura corporal negra de los visitantes, color de la sacralidad en Mesoamérica, que denota un gran poder político y religioso (Nava Román 2009). Además, portan cuchillos rituales excéntricos y andamios en la espalda que simbolizan los niveles verticales del cosmos (vid. Houston, Stuart y Taube 1992, p. 501-503, Helmke s.f.), entre ellos uno con forma de serpiente emplumada que parece relacionarse con el héroe cultural K'uk'chan o K'uk' [ul]kaan (Carter 2015, p. 11) quien, de acuerdo con el vaso, en 256 a.C. era un simpe sajal o un personificador ritual de la deidad (Boot 2016, p. 13-15).

En suma, aunque a primera vista la imagen parece representar una escena clásica de corte, donde los miembros de la procesión se asocian con el sacrificio, el sacerdocio y quizá la personificación ritual, tanto la fecha retrospectiva y su incongruencia intencional entre la Cuenta Larga y la Rueda de Calendario como el nombre propio de al menos uno de los individuos y el color rojo del fondo (asociado con la muerte), son recursos para ubicarla en los tiempos de la memoria arcana. Además, sospecho que el pintor de este vaso pudo haber fusionado u homologado intencionalmente dos momentos en una misma imagen a través de este entreverado sistema de recursos: las instituciones políticas ancestrales (de 256 a.C.) y las que existían en su propio tiempo, de principios del siglo VII. Erik Boot (2016) inclusive plantea la posibilidad de que estén fusionados tres momentos históricos. Por ello puede decirse que el pintor eligió representar estos acontecimientos sagrados del anecúmeno a través de las convenciones usadas para plasmar imágenes cortesanas mundanas del ecúmeno.

10. Dicha pintura roja es propia de todas las vasijas del llamado estilo de El Zotz (ca. 550-650), donde comúnmente se representaban espíritus wahyis y otros seres del anecúmeno, como también ocasionalmente humanos (vid. Carter 2015, p. 6-7). Alexander Tokovinine (2012, p. 290) asocia el color rojo con las calidades de calor o fiereza, componentes anímicos de origen solar. Dicho sea de paso, el calor y la fiereza son atributos de diversos seres wahyis (ver Sheseña Hernández 2010). Erik Boot (2016) enfatiza la vinculación del personaje principal y legendario del Vaso de la Serie Inicial de Uaxactún con el este. Y esa puede ser otra de las razones por las que el fondo del vaso es rojo, color vinculado con el oriente. 


\section{Imagen "antigua" e imagen "moderna"}

Una singular estrategia para representar el tiempo presente, humano y mundano del ecúmeno o ámbito de las criaturas en el lado derecho de la composición, pero el pasado en la mitad izquierda de la misma, ha sido notada por David S. Stuart (2013), usando como ejemplo la imagen del Monumento 171 de Toniná (Figura 3).

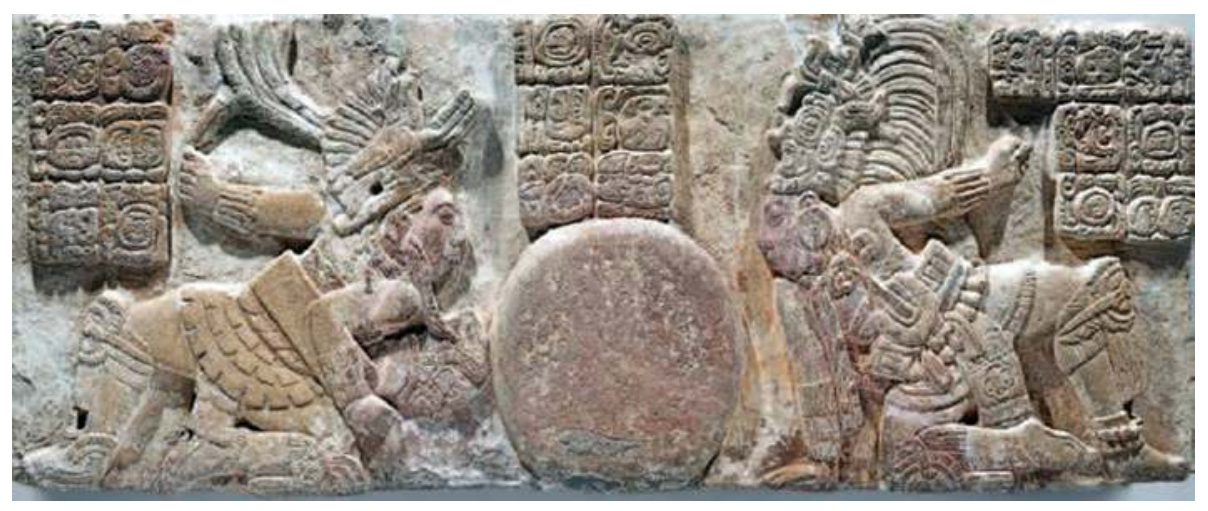

Fig. 3 - Los gobernantes de las ciudades aliadas Calakmul (K'ihnich Yihch'aak Chapaht) y Toniná (K'ihnich B'aaknal Chaahk) juegan a la pelota; Monumento 171 de Toniná (según foto INAH).

Una pelota de hule y una inscripción con la fecha 727 d.C. dividen la escena en dos mitades. A su derecha observamos al gobernante contemporáneo de Calakmul, Yuhkno'm Too'k' K'awiil, mientras que a la izquierda se ubica el fallecido señor de Toniná, K'ihnich B'aaknal Chaahk. Uno de los textos jeroglíficos de este bajorrelieve menciona al mandatario vivo y vigente de Toniná: K'ihnich Yihch'aak Chapaht, lo que sugiere que él patrocinó la escena en el año 727. Stuart supone que el soberano de Calakmul mencionado y representado en este documento pudo haber jugado a la pelota con ambos reyes de Toniná -el fallecido y el vigente-, y que esta manipulación de los tiempos en el texto y en la imagen tuvo el propósito de refrendar la alianza de Toniná con Calakmul, evocando un ritual ejecutado por el gobernante fallecido.

Conviene observar que en esta escena de Toniná (Figura 3), la imagen "antigua" se ubica en el flanco izquierdo de la composición, con un personaje cuyo rostro mira hacia la derecha, mientras que la imagen "moderna" o contemporánea ocupa el ala derecha respecto al espectador, espacio reservado para las figuras principales de la composición pues, como ha sugerido Stephen D. Houston (1998), el campo pictórico no era un espacio neutral o uniforme, sino dividido jerárquicamente según los cánones del arte maya. Del mismo modo, conviene 
apuntar que el rostro del personaje de la imagen contemporánea voltea hacia la izquierda, presentando la misma orientación que los jeroglíficos de la escritura maya. Lo que hace sospechar que los textos "en negativo", como el del Panel 1 de Laxtunich o el del Dintel 25 de Yaxchilán, donde las variantes de cabeza miran hacia la derecha, aluden a una realidad espacio-temporal distinta a la ordinaria o ecuménica de los humanos, aunque de momento esto es una hipótesis.

Otras escenas que juegan con el tiempo presente y el pretérito plasmándolos en el mismo plano, son los famosos tableros de la Cruz, Sol y Cruz Foliada (vid. Robertson 1991), donde la imagen del contemporáneo K'ihnich Kan B'ahlam II, a la presunta edad de 57 años, se encuentra del lado derecho del elemento temático central, ubicada sobre una banda celeste con símbolos diurnos, mientras que del lado izquierdo observamos al mismo personaje cuando sólo tenía 6 años, edad en la que eran designados los futuros herederos al trono. Conviene advertir que, en esas escenas de la infancia que evocan el pasado, el niño se encuentra de pie sobre una banda con símbolos nocturnos, lo que sugiere una relación entre cielo diurno y presente, por un lado, y entre cielo nocturno y pasado, por el otro. Además, es preciso remarcar que el infante de la imagen "antigua" se encuentra envuelto en telas con nudos y entrelaces, semejante al muerto que observamos en los funerales grabados en el célebre Vaso Trípode de Berlín (vid. Kerr 2000, p. 972). Como Stuart (1996, p. 156-157) ha sugerido, la práctica prehispánica de atar o envolver objetos, cuerpos o sustancias usando tela o papel, pudo tener el propósito de contener el tiempo y la esencia divina en el interior de esos continentes ${ }^{11}$.

Principios compositivos como éste pueden explicar las enigmáticas escenas de las vasijas de la tradición Ik'a', donde interactúan dos gobernantes diferentes de Motul de San José en el mismo plano pictórico (vid. Reents-Budet 1994, p. 60, 168, 170; Just 2012, p. 39, 47, 185-188, 190-191). Dichas imágenes probablemente son ceremonias ejecutadas por el mandatario Yehte' K'inich II, a la derecha (Figura 4), frente a su ancestro fallecido, K'ihnich Lamaw Ek', a la izquierda ${ }^{12}$. La estrategia también puede advertirse en el Altar Q de Copán (vid. Fash 2001, p. 24-25), donde el gobernante vivo Yahx Pasaj Chan Yopaat se ubica a la derecha de la composición, al tiempo que recibe el cetro de su remoto ancestro fallecido, K'ihnich Yahx K'uk' Mo', plasmado en la mitad izquierda.

11. De acuerdo con un revisor anónimo de mi texto, estos nudos y entrelaces también podrían relacionarse con los ritos de sacrificio y mutilación vinculados con la celebración de un futuro soberano.

12. Considero que esta interpretación, que toma en cuenta las convenciones del arte maya clásico, es más plausible que la hipótesis que formulé hace algún tiempo (Velásquez García 2011a), en el sentido de que el señorío de Ik'a' estuvo gobernado por un sistema de mandatarios binarios o simultáneos. 


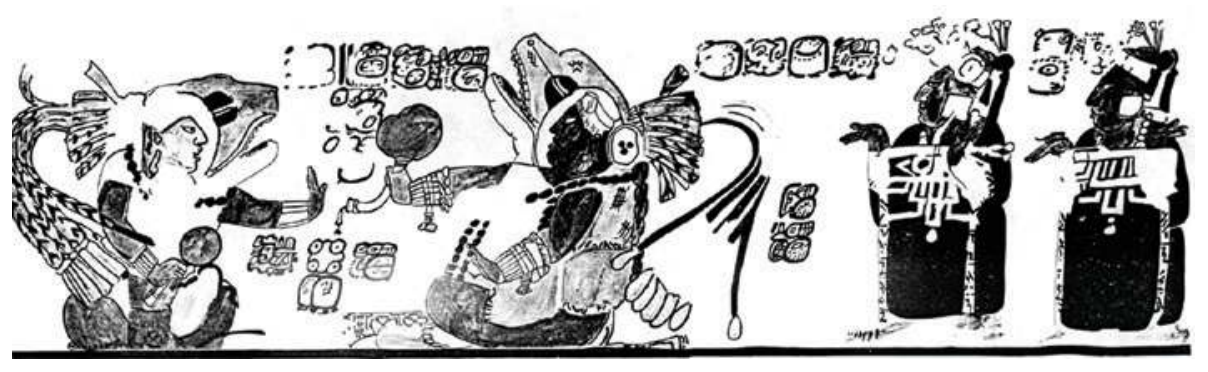

Fig. 4 - Vaso K3054 o LC-cb2-462, de la región del lago Petén Itzá, Departamento de Petén, Guatemala; San Antonio Museum of Art; dibujo de Persis Clarkson; fotografía y cortesía de Justin Kerr, tomada del archivo fotográfico de Kerr: http://research.mayavase.com/kerrmaya_hires.php?vase=3054.

\section{Yuxtaposición}

Un ejemplo más complejo de esta manipulación de tiempos se encuentra en la escena grabada en la Plataforma del Templo XXI de Palenque (vid. Bernal Romero 2003; Stuart 2006, p. 184-190; Stuart y Stuart 2008, p. 228-229). La imagen ilustra una ceremonia ocurrida en 736 d.C., pero el protagonista de la misma es el rey K'ihnich Janaab' Pakal I, quien llevaba casi 53 años de muerto (Figura 5).

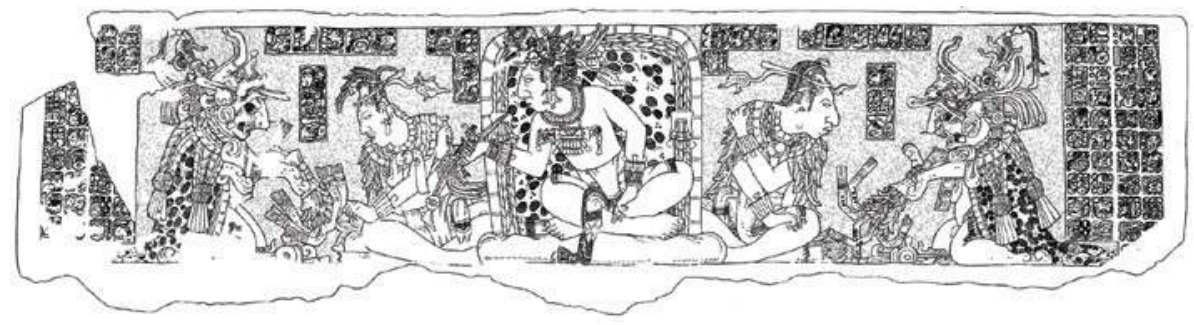

Fig. 5 - Imagen grabada en la Plataforma del Templo XXI de Palenque,

Chiapas, México; dibujo de David S. Stuart; tomado de Stuart (2006, p. 187).

Por si fuera poco, las glosas dicen que 'el señor de cinco $k$ 'atuunes, señor del árbol, K' ihnich Janaab' Pakal, rey divino de Palenque, es el representante de la entidad sagrada Ch'a... Ukokan Kan', un ancestro legendario que supuestamente gobernó en 252 a.C. (Bernal Romero 2013, p. 10; Garza Camino, Bernal Romero y Cuevas García 2012, p. 236). Finalmente, Janaab' Pakal se hace acompañar por dos de sus descendientes en el mando: K'ihnich Ahku'l Mo' Naahb' III (el comitente de la obra) y el príncipe Upakal K'ihnich Janaab' Pakal, que gobernaría después de él (vid. Martin y Grube 2008, p. 174; Garza Camino, 
Bernal Romero y Cuevas García 2012, p. 247-249). De manera que en esta compleja escena el pasado se ubica en el centro de la composición, flanqueado por dos habitantes del presente, mientras que en los extremos nuevamente figura un par de seres que se ubican en un tiempo-espacio liminar, pues se trata de representaciones de un sacerdote ataviado como la entidad sagrada Xak'al Mi'ht Tumu'y Tich'oj (Bernal Romero 2003, p. 19, 22; Garza Camino, Bernal Romero y Cuevas García 2012, p. 239).

La yuxtaposición de tiempos - pero también de espacios- es notoria en la escena del Dintel 2 del Templo 1 de Tikal, donde el gobernante Jasaw Chan K'awiil I personifica a un ancestro divinizado mediante una máscara de "rayos X” (vid. Velásquez García 2007, p. 12-15; 2009b, p. 362-366), ambientando la representación con vegetación del centro de México y confundiendo su identidad con la del presunto señor teotihuacano Jaatz'o'm Kuy o Búho Lanzadardos (Stuart 2000, p. 490; Montgomery 2001, p. 149-152; Guenter 2002, p. 226-227; Nielsen 2003, p. 244-245; Martin y Grube 2008, p. 45), quien se dice vivió dos siglos y medio antes.

Este ir y venir de tiempos y momentos puede advertirse en escenas de juego de pelota (vid. v. gr. Schele y Miller 1986, p. 250, 252, 255, 257-261, 263-264), donde la postura corporal del jugador (Figura 6), con el cuerpo inclinado, a punto o después de golpear el balón y apoyado en una sola rodilla, representa un instante elocuente ${ }^{13}$ sabiamente elegido por los artistas mayas, pues es el que con más eficacia sugiere lo que sucedió inmediatamente antes o lo que acaecería en el segundo siguiente.

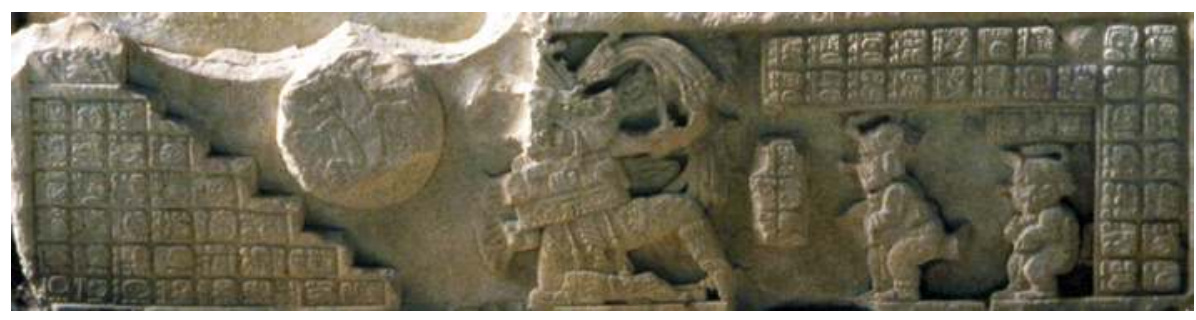

Fig. 6 - Escalón VII de la Escalera Jeroglífica 2 del Templo 33 de Yaxchilán, Chiapas, México; según foto INAH.

En una segunda dimensión temporal, Andrea J. Stone (1995, p. 198) ha sugerido que este tipo de escenas también representa dos momentos: 1) el rebote de la pelota por los taludes de la cancha y 2) el rito ulterior de arrojamiento de cautivos por las gradas de un edificio asociado con la cancha, pero distinto a ella,

13. Ver lo que más adelante explico sobre el recurso de la peripateia. 
ya que los espacios destinados para el juego generalmente carecen de escalones (vid. Velásquez García 2015a, p. 267). Dicha combinación visual simultánea de momentos sucesivos llegó a convertirse en una convención muy conceptual, pues "la forma escalonada también aparece en el jeroglífico de "juego de pelota" (Figura 7). A causa de que las evoluciones que realiza el cuerpo humano cuando era arrojado por las gradas de un edificio fueron equiparadas metafóricamente por los mayas con las del esférico de caucho, dichas escalinatas fueron consideradas simbólicamente como juegos de pelota (vid. Stuart 2003, p. 26).

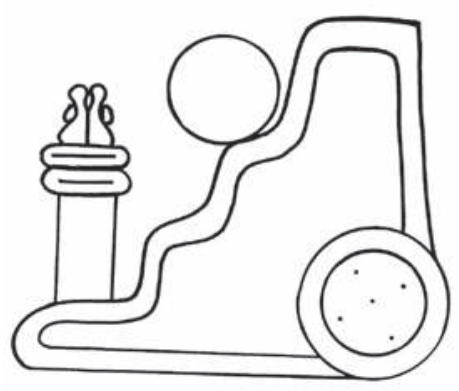

Fig. 7 - Sustantivo jalaab', 'juego de pelota'; Dintel 1 del Templo de los Cuatro Dinteles de Chichén Itzá (C8), Yucatán, México;

dibujo de Martha I. Sandoval Villegas, basada en Ruth Krochock (1989, p. 10).

Como cabría esperar, la yuxtaposición de tiempos conlleva también la yuxtaposición de espacios, fenómeno sutilmente representado en la imaginería maya a través de lo que Stephen D. Houston (1998, p. 344-345) y Mary E. Miller (1986, p. 147) llamaron "ángulos simultáneos de visión" o "ángulo de visión simultánea". Esto es el dibujo de las diversas partes del cuerpo vistas sincrónicamente desde perspectivas diferentes (Figura 8), lo que sólo lograríamos si nos desplazáramos alrededor de cada individuo, implicando distintos instantes en la mirada plasmados en un solo "golpe de vista" 14 . Se trata de un recurso que comparte algunos principios básicos con el cubismo, donde la anatomía se desdobla, presentando el cuerpo humano en torsiones imposibles, sacrificando la aspiración mimética en aras de la inteligibilidad visual.

14. Esta estrategia es un recurso que el arte maya clásico compartió con tradiciones de pintura aún más conceptuales, como por ejemplo el llamado estilo "internacional" del Posclásico o "Mixteca-Puebla", donde "el cuerpo humano es representado como un compendio de partes separables" (Smith 1973, p. 11), donde no era representado el modelo que se veía, sino el que se pensaba o "sabía" previamente, tal como explica Ernest H. Gombrich (2012, p. 66-68, 83-84) ocurre en otras tradiciones del mundo. La traducción de la cita de Mary E. Smith es mía. 


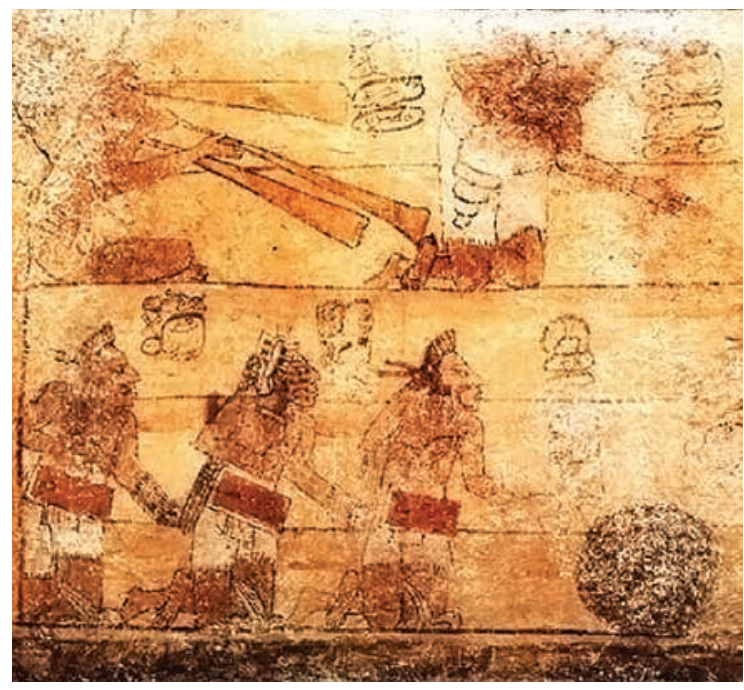

Fig. 8 - Detalle del vaso K3814. Los personajes adquieren posturas que sólo podrían observarse a través de un ángulo simultáneo de visión; detalle del vaso K3814;

fotografía y cortesía de Justin Kerr; tomada del archivo fotográfico de Kerr: http://research.mayavase.com/kerrmaya_hires.php?vase=3814.

Un ejemplo del ángulo de visión simultánea a gran escala se encuentra en la composición adoptada en el famoso friso de estuco de Toniná (vid. Yadeún Angulo 1992, p. 94-95), donde los seres wahyis se desplantan en una perspectiva casi frontal a la de los espectadores, mientras que la geografía de su mundo onírico - con sus caminos que se entrecruzan- se percibe desde arriba, a vuelo de pájaro. La proporción de estos cuerpos con respecto a la de su ambiente tampoco guarda relación natural, sino conceptual. De nueva cuenta, dos momentos o tiempos en la mirada se presentan en un solo y sincrónico "golpe de vista"15: una perspectiva usada para ver los personajes y otra para observar el entorno donde se incrustan, lo que de hecho se tornó en un modo de representación muy convencional cuya eficacia sin duda motivó su uso en varias regiones y épocas de Mesoamérica, como por ejemplo en el Patio Blanco de Atetelco (Teotihuacán), en el Monumento 32 de Tamtoc o en el folio $2 \mathrm{r}$ del Códice Mendocino.

Ingredientes mucho más profundos en esta yuxtaposición de tiempos fueron añadidos por los sabios escultores de Yaxchilán, quienes en el escalón VII de la Escalera Jeroglífica 2 (Figura 6) ubicaron un partido del gobernante Yaxuun

15. En realidad, no se trata de "un solo golpe de vista", pues las representaciones figurativas no verbales también son artes del tiempo, como lo expliqué en la introducción de este trabajo. 
B'ahlam IV y el posterior sacrificio por rodamiento de un cautivo en el marco del mismísimo orden cósmico (vid. Stuart 2003, p. 27; 2011, p. 246-247), pues la inscripción jeroglífica asociada alude a tres contiendas de pelota mitológicas donde la víctima siempre fue algún dios. De acuerdo con la propia inscripción, dichos acontecimientos del pasado profundo, que eran revitalizados por el gobernante vigente, tuvieron lugar en el Ik' Waynal, 'Lugar de la Cavidad Subterránea Negra', es decir, en la mitad oscura del universo, sitio de los ancestros y del sueño, ámbito del anecúmeno y, por tanto, región por excelencia del pasado.

A este respecto, conviene recordar que la gran escalinata jeroglífica de la Estructura 26 de Copán (vid. Baudez 1994, p. 217-232; Proskouriakoff 2002, p. 33-35; Fash 2001, p. 139-151; Stuart 2005, p. 382-386; Martin y Grube 2008, p. 208) contiene una crónica de la dinastía gobernante local, cuyos peraltes retroceden en el tiempo en la medida que uno asciende por las gradas. En otro lugar externé la idea de que aquellos privilegiados que ascendían esa escalinata retrocedían simultáneamente en el tiempo, a la vez que recorrían la senda que separaba el mundo de los hombres del de los dioses ${ }^{16}$.

Volviendo a las escenas de juego de pelota, Stuart (2003, p. 27) ha planteado que cada una de las decapitaciones del dios del maíz en el Ik' Waynal era seguida por un sustantivo ahaal, 'despertar', que en el lenguaje literario de estos mitos -y aún en los libros de Chilam Balam (vid. Montolíu Villar 1989, p. 22; Velásquez García 2009a, p. 56) - equivale a una nueva creación u ordenación del mundo, génesis del tiempo y fin de la intrascendencia divina, zona liminar entre el tiempo-espacio del anecúmeno y del ecúmeno (López Austin 2015a, p. 32; 2015b, p. 30-36). De manera que el origen del cosmos está también implicado en la escena del escalón VII de Yaxchilán (Figura 6).

La yuxtaposición de momentos en una imagen cuya visualidad es aparentemente sincrónica, se encuentra en innumerables escenas mayas. Un ejemplo son los llamados platos del danzante de Tikal (vid. Reents-Budet 1994, p. 197-198), que aparentemente representan la danza perpetuada por el dios del maíz cada vez que estaba a punto de renacer o germinar. Erik Boot (2003) ha observado que en algunos de esos platos, el llamado danzante de Tikal usa protectores sobre el cuerpo semejantes a los que llevaban los jugadores de pelota. En la Estela 1 de Bonampak (vid. Mathews 1980, p. 63) el mismo dios del maíz emerge por la hendidura del cerro del sustento, cuya cavidad es semejante al jeroglífico maya para juego de pelota. El renacimiento de este dios, como árbol o planta primigenia del maíz, es símbolo también del ordenamiento del tiempo y del espacio, lo mismo en mitos mayas precolombinos que del periodo virreinal (vid. Velásquez García 2009a). Todos estos momentos sucesivos, prefiguración los

16. "Reflexiones sobre el tiempo histórico en las inscripciones mayas", ponencia presentada en el marco de la VII Mesa Redonda de Palenque. Los mayas y las concepciones del tiempo, Palenque, Chiapas, México, 29 de noviembre de 2011. 
unos de los otros, pueden hallarse en la vasija K5226 (Figura 9), donde el numen del maíz danza mientras renace desde el interior de la montaña del alimento, cuya fisura es una conjugación de la cancha para el juego de pelota con las gradas donde eran arrojados los cautivos. Más interesante aún es el hecho de que el joven recién nacido sostiene entre sus brazos un par de serpientes de cuyas fauces surgen los llamados Dioses Remeros, un par de ancianos quienes en el panteón maya eran patronos de los momentos liminares (vid. Velásquez García 2010) y estaban asociados con la creación (Vail y Hernández 2013, p. 81).

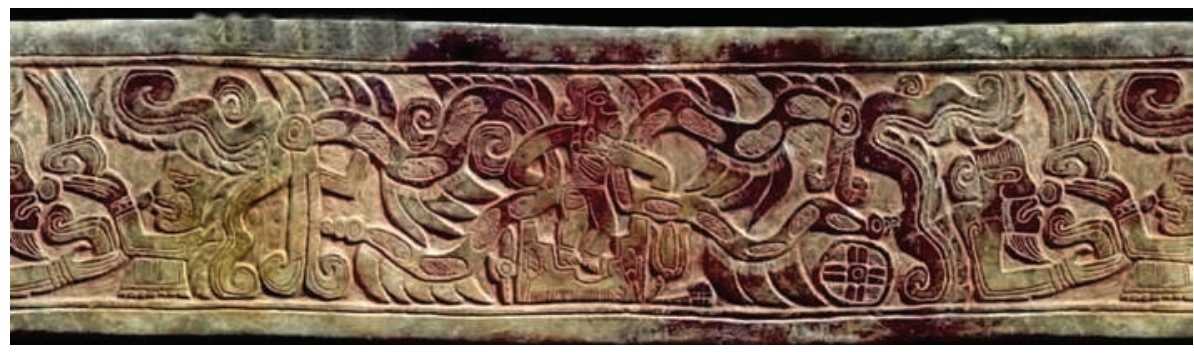

Fig. 9 - Dios E o Ju'n Ixiim naciendo de la cima de una montaña, que a su vez constituye la sima de la cancha de un juego de pelota; está ataviado como jugador de pelota e invoca a dos dioses ancianos, quienes surgen de las mandíbulas de serpientes; vaso K5226; Los Ángeles County Museum of Art; fotografía y cortesía de Justin Kerr; tomada del archivo fotográfico de Kerr: http://research.mayavase.com/kerrmaya hires.php? vase $=5226$.

\section{Metonimia}

Otra estrategia para representar la sucesión del tiempo en el arte maya, en parte distinta al recurso de yuxtaposición, es la metonimia, definida en la literatura como la "sustitución de un término por otro cuya referencia habitual con el primero se funda en una relación” (Beristáin Díaz 1997, p. 327), que puede ser de diversas clases, entre ellas del todo por la parte ${ }^{17}$. En el contexto de las artes visuales, puede definirse simplemente como el desplazamiento de la causa por su efecto (Carrere González y Saborit Viguer 2000, p. 306).

17. Alfonso Lacadena García-Gallo (2009, p. 41) detectó este recurso retórico en las inscripciones mayas y lo definió como la "referencia al todo [...] por la parte". Un buen ejemplo de metonimia es la famosa frase de muerte documentada por Tatiana A. Proskouriakoff (1963, p. 163), y que hoy podemos leer como K'A'-yi u-SAK-IK'-li, $k^{\prime} a$ ' [aa]y usak ik' [aa]l 'su aliento puro se perdió', en virtud de que el extravío del aliento vital aparentemente equivale fallecimiento del individuo completo. En este ensayo propongo la identificación del recurso de la metonimia en la imaginería maya no verbal. 
Un ejemplo al azar se encuentra en la Estela 3 de Aguateca (vid. Graham 1967, p. 17), cuyo texto menciona que el asunto principal de la escultura es un final de periodo calendárico donde el gobernante en turno celebró dos ritos: uchoko' $w$ ch 'aaj, 'tiró incienso', y uch 'ama 'w K'awiil, 'recibió el cetro maniquí'. En la escena no se encuentran representadas ninguna de las dos ceremonias como tales, sino el efecto inmediato de haber recibido el cetro del dios K'awiil, pues ya lo sostiene con la mano derecha. Este desvío o desplazamiento entre dos momentos diferentes (el que está mencionado en el texto y el que está representado en la imagen) es lo que explica por qué no existe relación uno a uno entre imagen y texto. El texto ayuda a comprender la imagen y esta última ayuda a entender el texto, pero no a través de una simple descripción verbal de la escena o de una representación de lo que está escrito, sino de una sucesión de causa y efecto. No hay razón para esperar que los artistas mayas usaran siempre los textos como si fueran glosas enunciativas de la iconografía.

Ejemplos de metonimia pueden hallarse en monumentos que abordan temas bélicos, como por ejemplo las estelas 2 de Aguateca y 16 de Dos Pilas (Graham 1967, p. 10,12), pues, mientras que las inscripciones mencionan las acciones castrenses, las imágenes iconográficas - no verbales-representan sus efectos o consecuencias, produciendo un elocuente desvío retórico: el desplazamiento de tiempos. Aunque en el texto de la Estela 2 de Aguateca (D2b-F7) se alude a que el prisionero de guerra Yihch'aak K'ahk', señor de Ceibal, 'fue adornado, afeitado' o 'embijado' ( $n a[h]$ waj) en presencia del señor de Dos Pilas (su preparación ritual), existe claramente un desplazamiento retórico respecto de la imagen, pues en esta última Yihch'aak K'ahk' ya luce pisoteado y humillado ${ }^{18}$. Este recurso sirve para acentuar el paso del tiempo al contener las causas y las consecuencias dentro de un flujo narrativo.

Otros documentos que contienen información bélica donde podemos apreciar el desplazamiento metonímico se encuentran en los peraltes del Edificio de los Cautivos de Dzibanché (Figura 10) que, como he explicado en su lugar, contienen imágenes de cautivos de guerra, pero no de los acontecimientos militares en sí mismos, que los llevaron a esa condición. Estos últimos se encuentran aludidos en el texto jeroglífico adjunto, el cual contiene la fecha y el verbo de invasión a sus ciudades de origen: och [i] uch'e'n, 'él entró a la ciudad' del cautivo.

18. Ana García Barrios (comunicación personal, 27 de octubre de 2016) sugiere que el propósito de dichas escenas no es mostrar al cautivo pisoteado, sino al gobernante de pie sobre los peraltes de las escalinatas que arrancan de las plazas púbicas. Desde esta perspectiva, las imágenes de los cautivos representarían en realidad los bajorrelieves labrados en las gradas. De tener razón García Barrios, la distancia entre el momento de la guerra (mencionado en las inscripciones de las estelas 2 de Aguateca y 16 de Dos Pilas) y esta ceremonia pública sobre escalones (representada en la imaginería de esas mismas estelas) sería aún mayor y por lo tanto el desplazamiento sería aún más acentuado. Mientras que la ceremonia de 'adornar, afeitar' o 'embijar' (naw) señalaría un momento intermedio. 


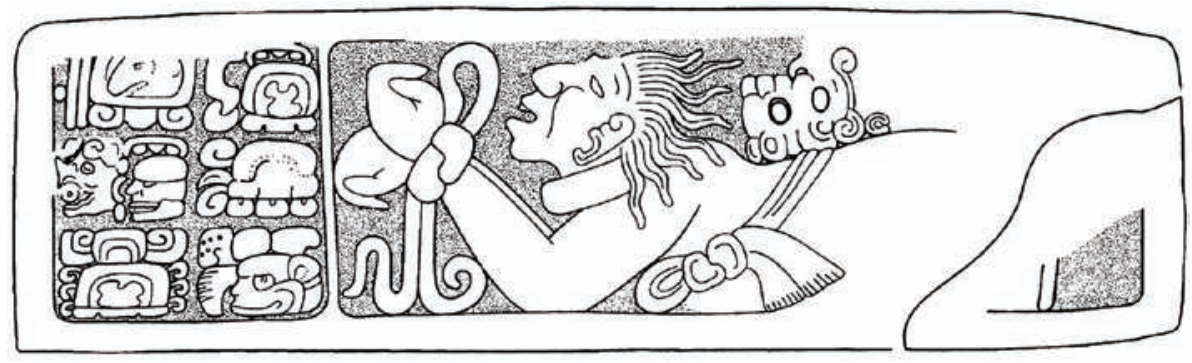

Fig. 10 - Monumento 5 de Dzibanché, Quintana Roo,

México; tomado de Velásquez García (2004, p. 87).

Una situación análoga es la que podemos encontrar en el Monumento 178 de Toniná (Figura 11), cuya inscripción menciona la derrota de Ajpitziil de Palenque y la ulterior captura de un individuo llamado K'awiil Mo', perpetradas ambas por los auspicios del gobernante K'ihnich B'aaknal Chaahk (Grube, Martin y Zender 2002, p. II-34). Ninguna de las dos acciones castrenses aparecen en la imagen, sino una de sus consecuencias más importantes: la exhibición del prisionero, ya inmovilizado mediante sogas. De nueva cuenta, el propósito de la imagen no es ilustrar lo que dice el texto en una relación uno a uno, ni la del texto repetir lo que está en la imagen, sino que ambos sistemas se complementan de otro modo: sugieren una secuencia temporal entre causas y efectos.

Los ejemplos de metonimia se podrían aducir con más prolijidad, detalle y abundancia, pero los límites de este artículo sólo permiten hacer una breve mención de este recurso retórico, esperando en el futuro realizar una exposición más copiosa y minuciosa.

\section{Secuencia in praesentia}

Otra estrategia para representar el devenir fue insinuada por Elizabeth P. Benson (apud Coe 1975, p. 24) hace más de cuatro décadas, inspirada en la

Fig. 11 - Monumento 178 de Toniná, Chiapas, México; dibujo de Simon Martin (tomado de Miller y Martin 2004, p. 185).

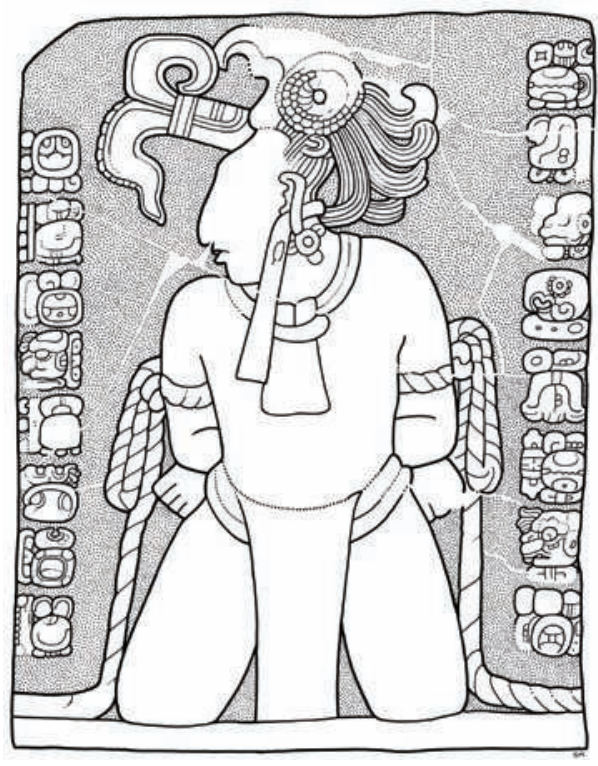


escena del vaso que hoy conocemos como K2784 (Figura 12). Consiste en pintar las acciones sucesivas de un solo personaje sobre la superficie de un mismo soporte, pero en tiempos diferentes, valiéndose de recursos de orden retratista, como plasmar al individuo vestido con atuendo semejante, adoptando idéntica postura, joyas, tocados o pintura corporal. Dorie J. Reents-Budet (1994, p. 150, 332) admitió la misma consonancia retratística entre ambas figuras representadas en viñetas diferentes del mismo vaso, aunque no llegó a afirmar que se trate de la misma persona plasmada en dos momentos distintos, probablemente a causa de que Michael D. Coe (1975, p. 24) había notado que las cláusulas jeroglíficas nominales de ambos personajes eran diferentes ${ }^{19}$, situación que fue ratificada por análisis más recientes (vid. Pillsbury et al. 2012, p. 318).

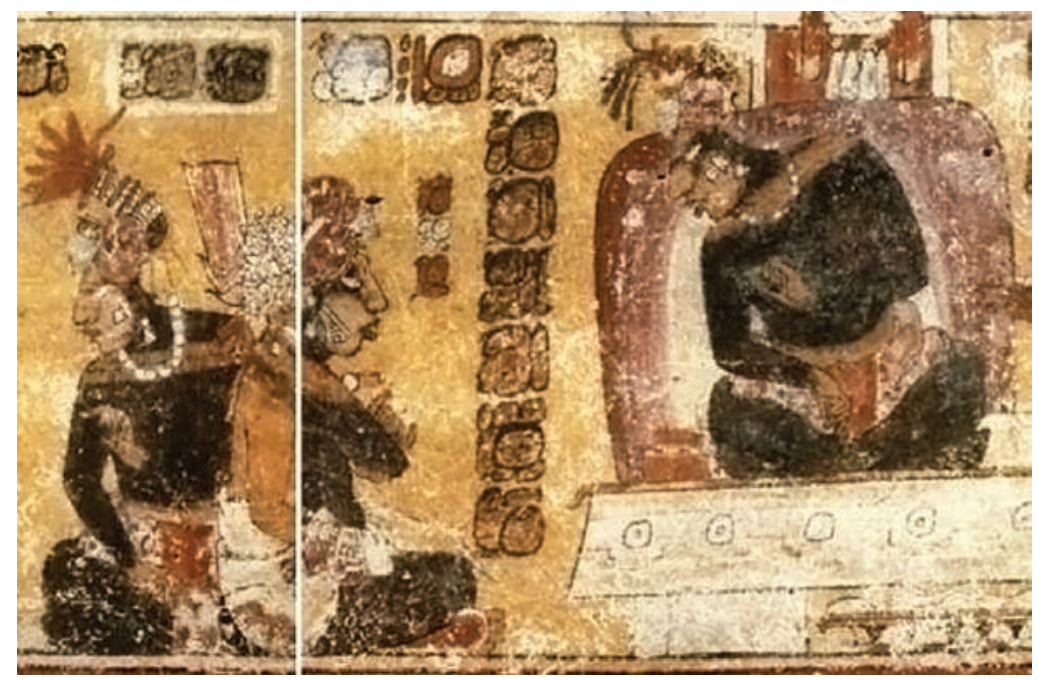

Fig. 12 - Dos personajes adoptan la misma postura y pintura corporal, atuendo y joyería en distintas viñetas de un mismo vaso, pero sus nombres jeroglíficos son diferentes. El personaje de la izquierda (a) se llama Ahk..., mientras que el de la derecha (b) es el gobernante K'in... Chaahk. Detalles del vaso MS445 o K2784, procedente del área del lago Petén Itzá, Departamento de Petén, Guatemala; Dumbarton Oaks Research Library and Collection, Washington, Distrito de Columbia, Estados Unidos de América, fotografía y cortesía de Justin Kerr; tomada del archivo fotográfico de Kerr: http://research.mayavase.com/kerrmaya_hires.php?vase=2784.

19. Michael D. Coe $(1975$, p. 24$)$ trató de conciliar este par de datos contradictorios (misma imagen, pero diferente glosa jeroglífica) a través de la idea de que podría tratarse de un pariente cercano del gobernante sentado sobre el trono, o incluso de un co-gobernante que compartía el poder con él, sistema político -señalaba- atestiguado etnohistóricamente entre distintas culturas mesoamericanas (vid. Velásquez García 2011a). 
Algunas reflexiones sobre la representación del tiempo

Sin embargo, la existencia de ese ejemplo fallido hace suponer que los artistas mayas efectivamente pudieron conocer el recurso sugerido por Benson. A este respecto, el Museo de Louvre contiene un ejemplo semejante para representar el tiempo (Figura 13). Se trata de un vaso estilo códice donde el dios del maíz agrede o ultraja a tres deidades distintas, que parecen ser los Dioses Remeros y el dios L. Si bien desconocemos los pormenores de esta narrativa mitológica, es obvio que tres de sus momentos fueron plasmados simultáneamente en este recipiente (vid. Velásquez García 2009c, p. 10, 12-14). Gracias a que hoy contamos con fotografías desplegadas o rollouts, frecuentemente pasamos por alto que se trata de un objeto tridimensional y de superficie convexa, donde el antiguo observador maya sólo podía apreciar de forma simultánea una de las escenas o viñetas. Para seguir la secuencia narrativa de estas tres escenas era necesario girar el recipiente, aunque ignoramos si existía un orden preferido por el observador maya o lo giraba de forma aleatoria ${ }^{20}$.

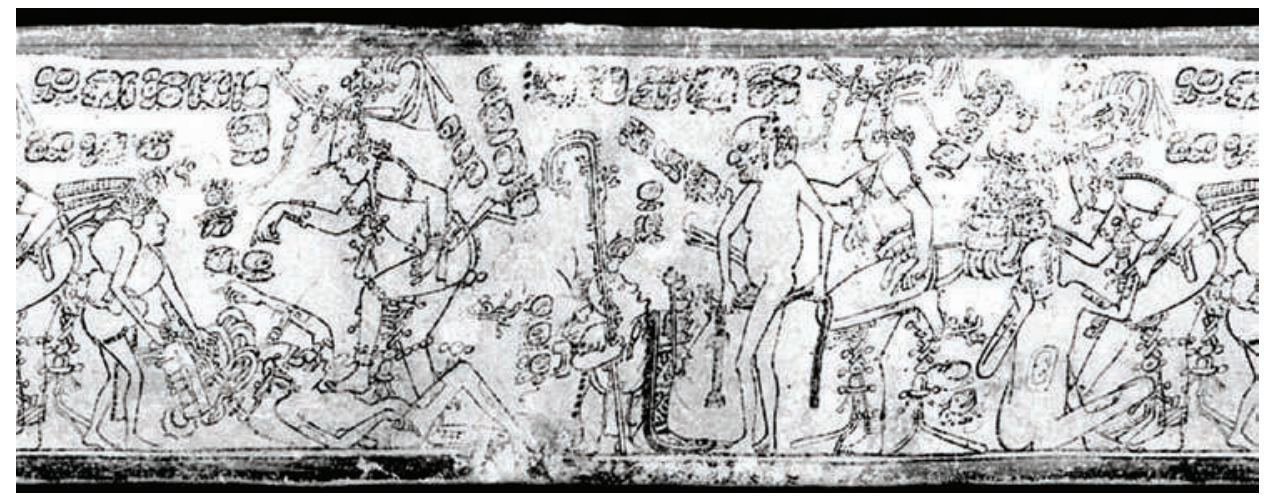

Fig. 13 - Vaso estilo códice K1560; Museo de Louvre, París, Francia, fotografía y cortesía de Justin Kerr, tomada del archivo fotográfico de Kerr: http://research.mayavase.com/kerrmaya_hires.php?vase=1560.

Si este recurso efectivamente fue parte del arsenal de estrategias instrumentadas por los artistas mayas, yo lo denominaría "secuencia in praesentia" "21, a causa de que los distintos momentos narrativos se encuentran atestiguados en un solo y mismo continente, de manera que el espectador no tiene necesidad de recurrir a otros documentos pictóricos.

20. Agradezco esta observación hecha por un dictaminador anónimo.

21. Término que he tomado de la obra de Carrere González y Saborit Viguer (2000, p. 118), quienes enfatizan que en una condición in praesentia las magnitudes de una pintura establecen relaciones "con otras magnitudes allí presentes". 
Semejante al anterior es el célebre Vaso Regio del Conejo (vid. Stuart y Stuart 1993, p. 170-171) que ha sido estudiado por varios autores (Figura 14) ${ }^{22}$. Dos momentos de la desventurada historia del dios L o Itzamaat se encuentran plasmados simultáneamente en esta vasija, repitiendo los mismos personajes: el conejo y el anciano, ambos con aspectos físicos semejantes en ambos lados del vaso. Aunque la novedad aquí reside en que largos textos jeroglíficos sirven para dividir este par de episodios narrativos.

Un ejemplo más de este recurso se encuentra en el vaso K8008 (Figura 15), que procede de la Tumba 116 de Tikal (vid. Culbert 1993, Fig. 84). Como argumentan Dmitri Beliaev y Albert Davletshin (2006, p. 33-34), basados en los trabajos de epigrafistas anteriores que han estudiado el vaso, los dos personajes plasmados en las viñetas opuestas son un colibrí e Itzamna'. Así se identifican gracias no sólo a que presentan atuendo, tocados y joyería semejantes en ambos lados del vaso, sino el mismo nombre jeroglífico: tz'unun, 'colibri' ${ }^{23}$, e Itzam Kokaaj(? $)^{24}$. Como estos autores argumentan, ambas escenas se refieren a dos momentos diferentes de la misma secuencia: en la primera el colibrí le dice a Itzamna' que el pinole se encuentra a la entrada del Sol, mientras que en la segunda se presenta frente a Itzamna' ya con el pinole o el atole hurtado. El colibrí funciona como un héroe cultural que consiguió esas bebidas de maíz.

En estos tres últimos vasos (Figuras 13-15) parece cumplirse el recurso vislumbrado hace décadas por Benson (apud Coe 1975, p. 24) para mostrar dos momentos diferentes sobre el mismo espacio pictórico, aunque todos aluden a temas de una época que los mayas creían anterior a la creación del hombre actual. Así que en sentido estricto no se trata de secuencias que se desarrollen en el tiempo-espacio del ecúmeno, sino en el del anecúmeno o zona procesual del mito (vid. López Austin 2015a, p. 31-32; 2015b, p. 27-30).

\section{Secuencia in absentia}

Por el contrario, es habitual tener en las vasijas pasajes aislados de una sola saga mitológica, como ocurre por ejemplo con el periplo transmundano del

22. Destaca sobre todos ellos el brillante trabajo de Dmitri Beliaev y Albert Daveltshin (2006, p. 22-29).

23. Tal como se aprecia en el trabajo de David S. Stuart y Stephen D. Houston (1994, p. 46, 49), la palabra tz'unun, 'colibrí', se encuentra escrita a través de un par de silabogramas y de una marca diacrítica: tz’u- ${ }^{2}$ nu. Vid. la tesis de maestría de Marc U. Zender (1999, p. 138).

24. La lectura del logograma ITZAM, presente tanto en el nombre del dios D, como en el N, así como en algunas advocaciones del dios L, se remonta a una carta que David S. Stuart le envió a Linda Schele (Stuart 1994). Simon Martin ha desarrollado más los argumentos que favorecen esta lectura a lo largo de distintas publicaciones y ponencias, desde 2006 hasta 2015, como también la parte que se refiere a KOKAJ. Vid. también el trabajo de Erik Boot (2008). 
Algunas reflexiones sobre la representación del tiempo

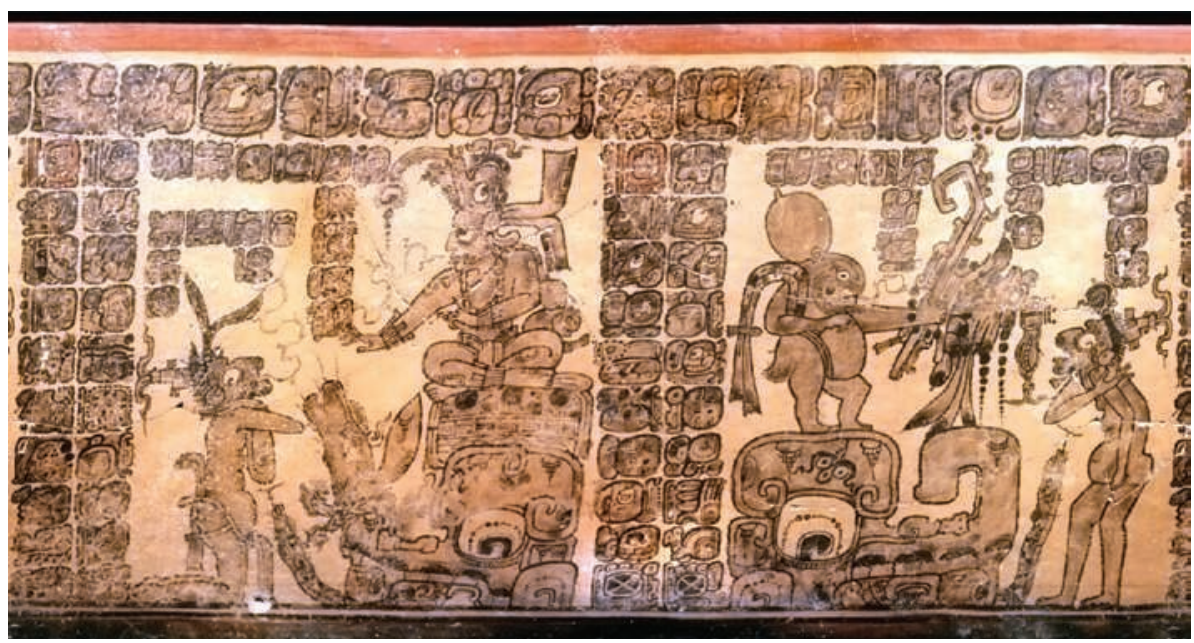

Fig. 14 - Vaso Regio del Conejo o K1398, que procede del área de Naranjo y se encuentra pintado en un estilo de tonos terrosos; fotografía y cortesía de Justin Kerr; tomada del archivo fotográfico de Kerr: http://research.mayavase.com/kerrmaya_hires.php?vase=1398.

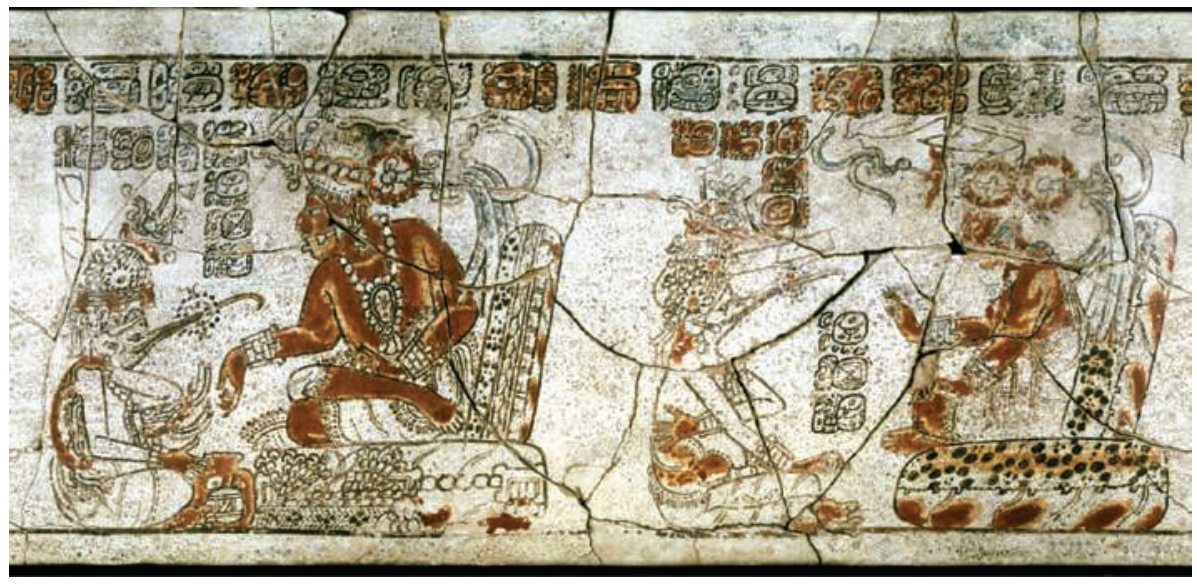

Fig. 15 - Vaso del Colibrí e Itzamna’ o K8008, hallado en el Entierro 196 de la Estructura 73 de Tikal; fotografía y cortesía de Justin Kerr; tomada del archivo fotográfico de Kerr:

http://research.mayavase.com/kerrmaya_hires.php?vase=8008. 
dios del maíz, estudiado hace años por Michel Quenon y Geneviève Le Fort $(1997)^{25}$, o los complejos entresijos de la Señora Dragón (Figura 16) en las vasijas estilo códice que, según Ana García Barrios y Rogelio Valencia Rivera (2011), forman parte del mito del Bebé Jaguar (Unen B'ahlam), así como el enfrentamiento de Ju'n Ajaw y Yahx B'alun contra Itzamna' cabalgando sobre un venado o pecarí, si es que, como proponen Beliaev y Davletshin (2006, p. 29-33), dicho mito tiene que ser reconstruido a partir de vasijas diferentes. Felix A. Kupprat ${ }^{26}$ considera que este recurso para representar distintos episodios en diferentes soportes es un ejemplo de sinécdoque (la parte por el todo), aunque yo propongo considerarlo como casos de "secuencia in absentia" 27 , en virtud de que el espectador tiene que acudir a otros textos escritos, verbales o visuales para armar la secuencia completa.

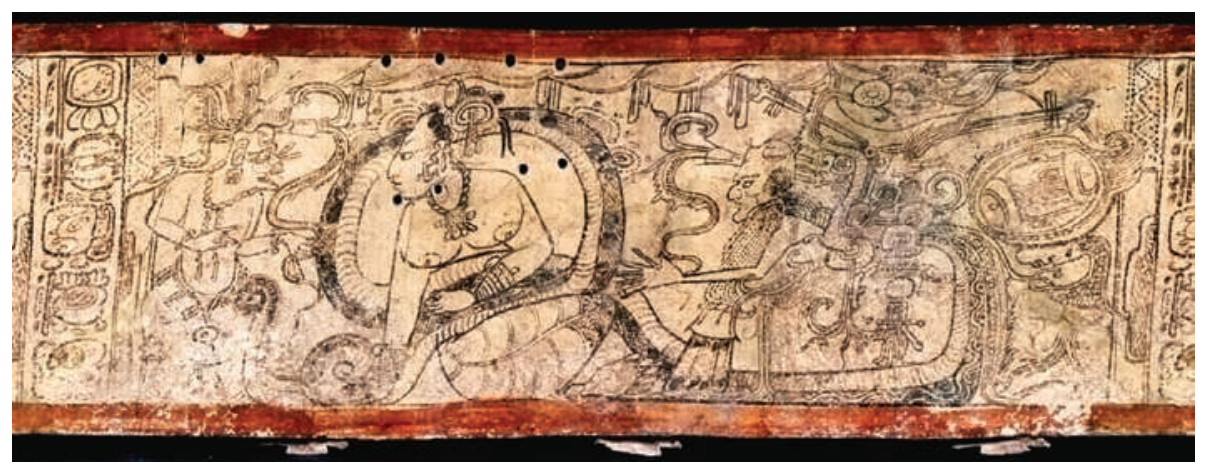

Fig. 16 - Pasaje de la saga mítica de la Señora Dragón y el Dios Viejo; vaso estilo códice K1198; fotografía y cortesía de Justin Kerr; tomada del archivo fotográfico de Kerr: http://research.mayavase.com/kerrmaya_hires.php?vase=1198.

25. Otros importantes trabajos reconstruyendo la saga del dios del maíz a través de la unión de diversas escenas han sido publicados: Karl A. Taube (1985, 2009), H. Edwin M. Braakhuis $(2009,2014)$ y Oswaldo Chinchilla Mazariegos (2011, p. 43-95).

26. "El texto, la imagen y el problema de la narrativa maya en el periodo Clásico", ponencia presentada en el marco de las Primeras Jornadas Académicas "Imagen y Escritura en Mesoamérica. Diferencias y relaciones entre ellas", Ciudad de México, Distrito Federal, México, 5 de septiembre de 2014.

27. Del mismo modo, he acuñado este término inspirado en la obra de Carrere González y Saborit Viguer (2000, p. 118). Según estos autores, in absentia alude a "magnitudes que, sin estar allí efectivamente presentes [...], son de alguna manera convocadas a la mente del espectador, como realizador de significados". 
Algunas reflexiones sobre la representación del tiempo

\section{Peripéteia}

Algunos vasos de la tradición Ik'a', como por ejemplo el K1439 (vid. ReentsBudet 1994, p. 166), insinúan otro recurso para sugerir el paso del tiempo en la imaginería maya. Se trata de producir en el espectador la sugestión del movimiento, cambio y viraje del cuerpo, eligiendo posturas dinámicas y cadenciosas, que se conectan con otros individuos de la misma escena involucrados en un instante diferente de la misma acción (Figura 17): en este caso dos danzantes esbeltos que se hacen eco entre sí a través de delicados y gráciles movimientos del dorso y de las extremidades, flanqueando la figura del obeso y estático protagonista, produciendo una cierta tensión y contraste entre estabilidad y cambio ${ }^{28}$.

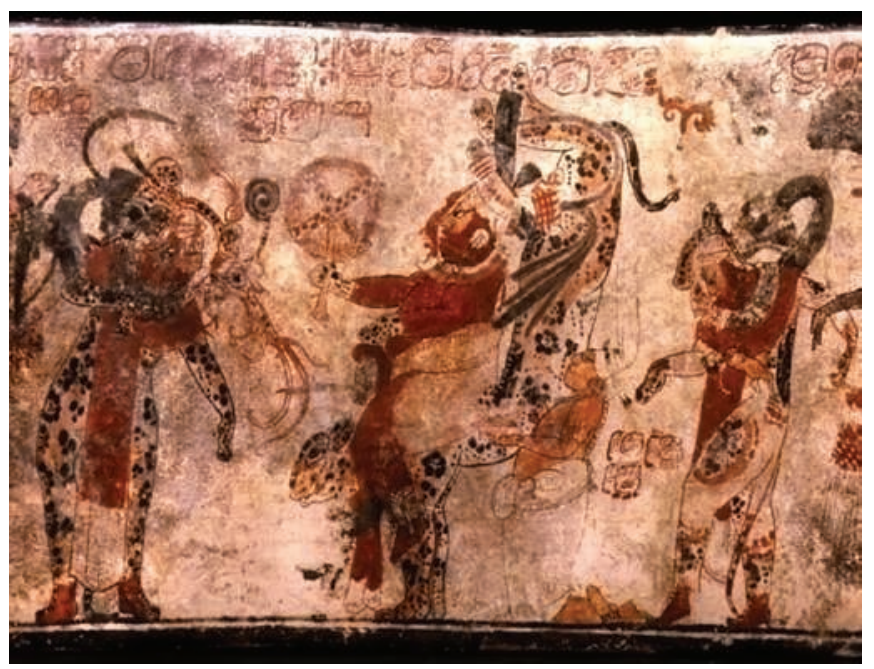

Fig. 17 - Detalle del vaso K1439, que procede de la región del lago Petén Itzá,

Departamento de Petén, Guatemala; Museum of Fine Arts de Boston, Massachusetts, Estados Unidos de América; fotografía y cortesía de Justin Kerr; tomada del archivo fotográfico de Kerr: http://research.mayavase.com/kerrmaya_hires.php?vase=1439.

La eficacia de este recurso obedece en parte al uso de otra estrategia llamada peripéteia $(\pi \varepsilon \rho \iota \dot{\varepsilon} \tau \varepsilon 1 \alpha)$, "momento elocuente" o "instante narrativo", que resulta de potencial ayuda en el ámbito de estudio de la Historia del Arte para resolver problemas de causa y efecto, ayudando a captar el carácter narrativo de las

28. Dicho contraste se acentúa en este vaso maya en particular, gracias al elástico felino contorsionista que sirve para que el gobernante obeso ejecute la danza del t'olol b'ahlam (t'o-lo B'ALAM-ma) o 'jaguar en ringlera'. 
imágenes. Durante la Antigüedad clásica, los griegos -especialmente en la tragedia- usaban el vocablo peripéteia, peripáteia o peripecia para definir un hecho imprevisto, de incidentes espantosos o lamentables, que implicaba la caída de un ser humano, desde las alturas de su fortuna, hasta su ruina, o desde su fortaleza hasta su vulnerabilidad. Es decir, peripéteia implicaba una suerte de inversión en la trama, problema que ya le preocupaba al mismo Aristóteles en la Poética (1946), al tratar de formular una teoría dramática del tiempo representado en el teatro, cazando unidades de tiempo-acción y lugar en la escena ${ }^{29}$. Según Aristóteles $\pi \varepsilon \rho \iota \pi \dot{\varepsilon} \varepsilon \varepsilon 1 \alpha$ o peripecia "es la inversión de las cosas en sentido contrario", misma que "debe acontecer por necesidad o según probabilidad"

como en el Edipo [Rey, de Sófocles] se ve, que el que vino a confortarle y librarle del temor que tenía por lo de su madre, en habiendo mostrado quien era, le causó contrario efecto; y en el Linceo [tragedia de Teodecto de Faselis] se lleva a la muerte a Linceo y va siguiéndole Dánao para matarlo; pues bien, el curso de los acontecimientos hace que éste muera y aquél se salve (Aristóteles 1946, p. 16).

Peripéteia o peripecia consistía, pues, en trocarse acontecimientos prósperos en adversos o aciagos en venturosos a partir de la contextura misma de la trama o del argumento (ibídem, p. 12-13, 16) ${ }^{30}$. Según el punto de vista de Aristóteles $(1946$, p. 27,39$)$, toda epopeya o tragedia contiene un argumento o trama compuesto por tres partes: 1) nudo (que abarca desde el principio hasta el momento donde se trueca la suerte hacia buena o hacia malaventura), 2) peripecia o peripéteia (viraje, inversión o movimiento), y 3 ) desenlace (que va desde el comienzo de tal inversión hasta el final). En otras palabras, $\pi \varepsilon \rho \imath \pi \dot{\varepsilon} \tau \varepsilon 1 \alpha$ es el instante elocuente dentro de un flujo narrativo, aquel en el que subyace la clave emocional del movimiento, del tiempo y de la acción en el arte ${ }^{31}$.

Víctor Burgin ha estudiado la aplicación de este recurso en el ámbito de la interpretación de la pintura. Según él, el concepto de peripéteia marca "la coyuntura decisiva o momento narrativo que un pintor selecciona, el segundo

29. Jaime G. Cuadriello Aguilar, comunicación personal, 4 de agosto de 2012.

30. Estos cambios de fortuna son una especie de castigos o premios poéticos que, según Aristóteles (1946, p. 19), han de sucederles a personas cuya bondad o maldad no sea excesiva, sino ordinaria, pues "no se distinguen particularmente ni en virtud ni en justicia"; y dichos cambios de fortuna en la tragedia no deben suceder por faltas, maldad o perversidad, "sino por un error" o "grande yerro del personaje", "para que así no se ofrezcan en el teatro espectáculos bochornosos, humanamente ofensivos" (1946, LXXXI). En estas valoraciones morales subyace el vínculo que tiene la peripéteia con otra de las grandes obras de Aristóteles: la Ética nicomáquea.

31. Añade Aristóteles que este recurso se encuentra entre los "que más habla al alma", puesto que produce entre los espectadores compasión o temor; la primera inspirada en lo inmerecido de la desdicha y el segundo fundado en la semejanza (1946, p. 10, 17-18); es decir, el éxito del viraje poético o $\pi \varepsilon \rho ı \pi \dot{\varepsilon} \varepsilon \varepsilon \imath \alpha$ obedece a que conjunta el efecto trágico con la emoción humana (ibídem, p. 29). 
Algunas reflexiones sobre la representación del tiempo

elocuente". Es "un instante capturado dentro de, abstraído de, un flujo narrativo" (Burgin 1986, p. 99).

Es la razón por la que el concepto peripéteia ha sido tan explotado recientemente entre los teóricos de la fotografía (vid. Colorado Nates 2011), uno de los cuales, Terence Wright, lo define inmejorablemente de la siguiente forma:

Es la imagen estática, que acaba siendo una imagen memorable. La captura del tiempo, una porción temporal y espacial del pasado, que queda capturada en un permanente estado de presencia [Mediante el recurso de peripéteia un pintor puede fijar] el momento en el presente continuo que permite al espectador, a su antojo, tomarse el tiempo para especular (o fantasear) sobre un hecho que podría no percibirse del mismo modo en el curso normal de los acontecimientos [dando así] una mínima indicación de la causa y efecto de lo que vemos. Este momento capturado, que no puede volver a repetirse, ha quedado asegurado mediante la [pintura o la fotografía] para su reproducción y observación repetida [A través de este recurso, la pintura y la fotografía] hace posible que algunos aspectos de nuestra percepción sobrevivan al tiempo. Ofrece la oportunidad al espectador de ir más allá de los límites de la percepción cotidiana, otorgándole el tiempo y el espacio para imaginar, examinar o analizar [...] La información derivada del momento queda así separada de su contexto y fijada en el tiempo (Wright 2001, n. 84).

En esto reside el meollo de la peripéteia, pues la pericia y experiencia del artista, al usar eficazmente los recursos expresivos de la tradición pictórica que había absorbido en su taller de maestros y aprendices, le proporciona intuitivamente el conocimiento preciso para elegir el mejor instante, aquel que pudiera sugerir -con más elocuencia e intensidad- el efecto de causa y efecto, de motivo y consecuencia, generando una imagen narrativa.

Fue alrededor de 790 d.C. cuando los versados pintores de Bonampak llevaron a sus límites del recurso de la peripéteia, produciendo el efecto de una secuencia cuadro a cuadro al plasmar el movimiento agitado y repetitivo de las maracas en los muros del Cuarto 1 (Figura 18), pues cada uno de los ejecutantes adopta un instante elocuente que prefigura al de su compañero. En palabras de Mary E. Miller y Megan O’Neil (2014, p. 220-221), en esta escena los artistas mayas se adelantaron a los registros fotográficos de la figura humana en movimiento mediante la técnica del cuadro por cuadro, instrumentada hasta el siglo XIX.

\section{Reflexiones finales}

Hemos visto cómo los artistas mayas convirtieron las artes visuales en elocuentes y eficaces artes del tiempo, usando para ello un amplio repertorio de recursos. Dada la extensión de este artículo, tan sólo hemos podido mencionar un puñado de ellos: la manipulación de fechas, la yuxtaposición de distintos momentos en una sola composición o plano, la bilateralidad izquierda (pasado)derecha (presente), la representación de escenas míticas usando convenciones 


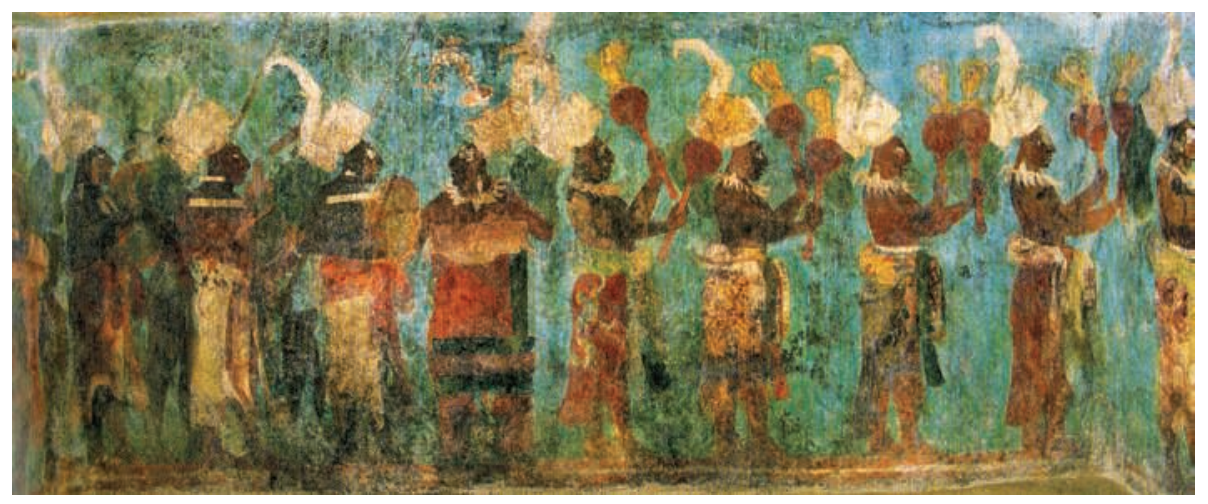

Fig. 18 - Detalle del Cuarto 1 de la Estructura 1 de Bonampak, lado norte, Chiapas, México (ca. 791 d.C.); Archivo fotográfico del proyecto "La pintura mural prehispánica en México", Instituto de Investigaciones Estéticas de la Universidad Nacional Autónoma de México: fotografía de Ernesto Peñaloza Méndez (1997).

que habitualmente sirven para plasmar hechos mundanos, el desvío retórico o metonímico, la secuencia in praesentia, la secuencia in absentia y la elección del instante elocuente o peripéteia. Las composiciones autocontenidas y las de carácter narrativo señaladas por de la Fuente (2004), y que apenas dio tiempo de explicar someramente al principio de este trabajo, representan como ninguna la fusión inextricable e indisoluble que los mayas veían entre el tiempo y el espacio. Desde un punto de vista político, para los artistas mayas eran de singular importancia las imágenes "antiguas", mismas que se ubicaban retrospectivamente en la mitad oscura del mundo, el anecúmeno, o región onírica del pasado, de la noche, del cielo estrellado y de los ancestros, perceptible sólo mediante los ojos clarividentes del sueño y posiblemente del trance. La imagen "moderna", por su parte, pertenecía al ámbito del ecúmeno, "casa de las criaturas" o presente inmediato, a la vigilia, al cielo diurno y podía aún ser percibida con los sentidos ordinarios, pero era sólo consecuencia o efecto de las causas antiguas.

Esta imagen se completa cuando consideramos el punto de vista lingüístico que se deriva del análisis de las inscripciones jeroglíficas mayas, donde las formas verbales incompletivas son extraordinariamente raras y el estilo literario favoreció el aspecto completivo (Lacadena García-Gallo 2010, p. 14-15). Esto incluso en verbos que a través de las fechas están ubicados en el futuro, como uhto' $m$, donde el gramema -o'm sólo indica un tipo de participio para predicados ubicados en el porvenir, pero que ya se han completado. De ahí que la traducción literal de esta expresión sea: 'habrá de estar ocurrido' o 'habrá 
Algunas reflexiones sobre la representación del tiempo

ocurrido' (op. cit., p. 20), no 'ocurrirá'. Ello indica por otro camino que para el hombre maya el presente, y aún el futuro, ya se habían consumado en el pasado, aunque es muy probable que esta afirmación no pueda generalizarse a todos los grupos mayances de las épocas moderna y contemporánea, sino sólo a los mayas precoloniales. Al menos por lo que se refiere a las lenguas chujeanas, la palabra tza'ani equivale a "futuro", pero significa literalmente 'lo que está detrás' (Schumann Gálvez 1981, p. 135; Velásquez García 2009a, p. 68, n. 56).*

* Manuscrit reçu en janvier 2016, accepté pour publication en octobre 2016.

Este artículo forma parte del número especial Compases y texturas del tiempo entre los mayas: lo dicho, lo escrito, lo vivido.

Agradecimientos - Deseo agradecer y reconocer a la Dirección General de Asuntos del Personal Académico (DGAPA) de la UNAM, por el apoyo recibido durante el tiempo de elaboración de este artículo, a través del Programa de Apoyo a Proyectos de Investigación e Innovación Tecnológica (PAPIIT) intitulado "Las escrituras jeroglíficas maya y náhuatl: desciframiento, análisis y problemas actuales”, que lleva la clave IN402213. Gracias a mis amigos y colegas Erik Boot, Jaime G. Cuadriello Aguilar, Ana García Barrios, Alfonso Lacadena García-Gallo y Rodrigo Martínez Baracs, así como a un par de sabios dictaminadores anónimos, por los invaluables comentarios que me hicieron. Agradezco también a Justin Kerr, David S. Stuart, Simon Martin, Nikolai Grube por la ayuda y generosidad que tuvieron conmigo en el proceso de adquisición de los derechos de las imágenes, a los integrantes del Proyecto la Pintura Mural Prehispánica en México del Instituto de Investigaciones Estéticas de la UNAM, por haberme concedido los derechos de la Figura 18, así como a mi esposa Martha I. Sandoval Villegas, autora de la Figura 7. Finalmente agradezco a Dominique Michelet, Fabienne de Pierrebourg y Valentina Vapnarsky por el interés y paciencia infinita que tuvieron al esperar mi trabajo.

\section{Referencias citadas}

Ayala Falcón Maricela

1985 El fonetismo en la escritura maya, Universidad Nacional Autónoma de MéxicoInstituto de Investigaciones Filológicas-Centro de Estudios Mayas (Cuaderno, 17), México.

ARISTÓteles de Estagira

1946 Poética, versión directa, introducción y notas por Juan Dávid García Bacca, Universidad Nacional Autónoma de México (Bibliotheca Scriptorum Graecorum et Romanorum Mexicana), México.

BAudEz Claude-François

1994 Maya Sculpture of Copán. The Iconography, University of Oklahoma Press, Norman/Londres.

Beliaev Dimitri

2011 "El tiempo histórico y el tiempo mítico en las narraciones mayas clásicas", ponencia presentada en el marco de la VII Mesa Redonda de Palenque. 
Los mayas y las concepciones del tiempo, Palenque, Chiapas, México, 29 de noviembre de 2011.

Beliaev Dimitri y Albert Davletshin

2006 "Los sujetos novelísticos y las palabras obscenas: los mitos, los cuentos y las anécdotas en los textos mayas sobre cerámica del periodo Clásico", in Rogelio Valencia Rivera y Geneviève Le Fort (eds), Sacred Books, Sacred Languages. Two Thousand Years of Ritual and Religious Maya Literatura. Proceedings of the 8th European Maya Conference. Madrid, November 25-30, 2003, Verlag Antón Saurwein, Markt Schwaben (Acta Mesoamericana 18), p. 21-44.

Beristáin DíAz Helena

1997 [8 éd.] Diccionario de retórica y poética, Editorial Porrúa, México.

BERnAL Romero Guillermo

2003 El trono de Ahkal Mo' Nahb' III. Un hallazgo trascendental en Palenque, Chiapas, Consejo Nacional Para la Cultura y las Artes-Instituto Nacional de Antropología e Historia/Nestlé México/Secretaría de Desarrollo Social, México.

Bоот Erik

2003 “An Annotated Overview of 'Tikal Dancer Plates"”, Mesoweb, www.mesoweb. com/features/boot/TikalDancerPlates.pdf.

2008 "At the Court of Itzamnah Yax Kokaj Mut: Preliminary Iconographic and Epigraphic Analysis of a Late Classic Vassel”, Maya Vase [on-line], www. mayavase.com/God-D-Court-Vessel.pdf.

2016 "On the Preclassic Origin of the Kaanu'l Dynasty: The Uaxactun Vase and Lamanai Stela 9 Revisited", manuscrito fechado el 17 de noviembre de 2016.

BraAkhuis H. Edwin W.

2009 "The Tonsured Maize God and Chicome-Xochitl as Maize Bringers and Culture Heroes: A Gulf Coast Perspective", Wayeb Notes [on-line], 32, http:// www.wayeb.org/notes/wayeb_notes0032.pdf.

2014 “Challenging the Lightnings: San Bartolo's West Wall Mural and the Maize Hero Myth", Wayeb Notes [on-line], 46, http://www.wayeb.org/notes/wayeb_ notes0046.pdf.

BURGIN Victor

1986 "Diderot, Barthes, Vertigo", in Victor Burgin, James Donald, Cora Kaplan (eds), Formations of Fantasy, Methuen, Londres/Nueva York, p. 85-108.

Carrere González Alberto y José Saborit Viguer

2000 Retórica de la pintura, Cátedra, Madrid.

CARTER Nicholas P.

2015 "Once and Future Kings: Classic Maya Geopolitics and Mythic History on the Vase of the Initial Series from Uaxactun", The PARIJournal, XV (4), p. 1-15.

Chinchilla Mazariegos Oswaldo

2011 Imágenes de la mitología maya, Universidad Francisco Marroquín-Museo Popol Vuh, Guatemala.

CoE Michael D.

1975 Classic Maya Pottery at Dumbarton Oaks, Dumbarton Oaks/Trustees for Harvard University, Washington. 
Algunas reflexiones sobre la representación del tiempo

2010 El desciframiento de los glifos mayas, nueva edición, Fondo de Cultura Económica, (Sección de Obras de Antropología), México.

Colorado Nates Óscar

2011 “El 'instante decisivo’ de Henri Cartier-Bresson”, Óscar en fotos [en línea], http://oscarenfotos.com/tag/peripateia/

Culbert T. Patrick

1993 The Ceramics of Tikal: Vessels from the Burilas, Caches, and Problematical Deposits, University of Pennsylvania/The University Museum, (Tikal Report, 25), Filadelfia.

FASH William L.

2001 Scribes, Warriors and Kings. The City of Copán and the Ancient Maya, edición revisada, Thames and Hudson, Nueva York.

Fuente Beatriz de la

2004 "Espacio y tiempo en el arte", in Virginia Guedea Rincón Gallardo (ed.), El historiador frente a la historia. El tiempo en Mesoamérica, Universidad Nacional Autónoma de México-Instituto de Investigaciones Históricas, México, p. 53-69.

García Barrios Ana

2006 "Confrontation Scenes on Codex-Style Pottery: An Iconographic Review", Latin American Indian Literature Journal. An Review of American Indian Texts and Studies, 22 (2), p. 129-152.

García Barrios Ana y Rogelio Valencia Rivera

2011 "Relaciones de parentesco en el mito del dios Viejo y Lady Dragón: las cerámicas estilo códice", in Merideth Paxton y Manuel A. Hermann Lejarazu (eds), Texto, imagen e identidad en la pintura maya prehispánica, Universidad Nacional Autónoma de México-Instituto de Investigaciones Filológicas-Centro de Estudios Mayas (Cuaderno, 36), México, p. 63-87.

Garza Camino Mercedes, Guillermo Bernal Romero y Martha Cuevas García

2012 Palenque-Lakamha'. Una presencia inmortal del pasado indígena, Fondo de Cultura Económica/El Colegio de México/Fideicomiso Historia de las Américas, México (Sección de Obras de Historia).

GOMBrich Ernst Hans

2012 Historia de arte, traducción al español de R. Santos Torroella, $7^{\mathrm{a}}$ reimp. de la $16^{\text {a }}$ ed. en español, Phaidon Press Limited, Barcelona.

GraHAm Ian

1967 Archaeological Explorations in El Peten, Guatemala, Tulane University (Middle American Research Institute, Publication 33), New Orleans.

1982 Corpus of Maya Hieroglyphic Inscriptions, vol. 3, part. 3. Yaxchilán, Harvard University-Peabody Museum of Archaeology and Ethnology, Cambridge.

Grube Nikolai

2004 "El origen de la dinastía Kaan”, in Enrique Nalda Hernández (ed.), Los cautivos de Dzibanché, Consejo Nacional para la Cultura y las Artes-Instituto Nacional de Antropología e Historia, México, p. 117-131. 
Grube Nikolai y Simon MarTin

2001 "The Coming of Kings. Writing and Dynastic Kingship in the Maya Area Between the Late Preclassic and Early Classic", in Notebook for the XXVth Maya Hieroglyphic Forum at Texas, March 2001, The University of Texas at Austin-Maya Workshop Foundation, Austin.

Grube Nikolai, Simon Martin y Marc U. Zender

2002 "Palenque and its Neighbors", in Notebook for the XXVIth Maya Hieroglyphic Forum at Texas, March 2002, The University of Texas at Austin-Maya Workshop Foundation, Austin.

GUENTER Stanley Paul

2002 Under a Falling Star: the Hiatus at Tikal, tesis de maestría, La Trobe University, Faculty of Social Sciences, School of Archaeology, Bundoora.

2004 "Gobernantes preclásicos en la Cuenca del Mirador", ponencia presentada en el marco del XVIII Simposio de Investigaciones Arqueológicas en Guatemala, Ciudad de Guatemala, Departamento de Guatemala, Guatemala, 22 de julio de 2004.

Helmke Christophe

s.f. "An Analysis of the Imagery and Text of the Cuychen Vase", in Christophe Helmke (ed.), Speleoarchaelogical Investigations in the Maya River Valley, Belize, Pre-Columbian Mesoweb Press, San Francisco, en preparación.

Houston Stephen D.

1998 "Classic Maya Depictions of the Built Environment", in Stephen D. Houston (ed.), Function and Meaning in Classic Maya Architecture. A Simposium at Dumbarton Oaks, 7th and 8th October 1994, Dumbarton Oaks Research Library and Collection, Washington, p. 333-372.

Houston Stephen D., David S. Stuart y Karl A. Taube

1992 "Image and Text on the "Jauncy Vase", in Justin Kerr (ed.), The Maya Vase Book, vol. 3, Kerr Associates, Nueva York, p. 498-512.

Jones Christophe y Linton SATTERThwAite

1983 Tikal Report, $\mathrm{n}^{\circ} 33$, part A, The Monuments and Inscriptions of Tikal: The Carved Monument, The University of Pennsylvania Museum, Filadelfia.

Just Bryan

2012 Dancing into Dreams. Maya Vase Painting of the Ik' Kindom, con contribuciones de C. T. Halperin, A. E. Foias y S. Nunberg, Yale University Press, New Haven/Londres.

KERR Justin

2000 The Maya Vase Book, Kerr Associates, Nueva York, vol. 6.

KROCHOCK Ruth

1989 “Hieroglyphic Inscriptions at Chichen Itzá, Yucatán, México: The Temples of the Initial Series, the One Lintel, the Three Lintels, and the Four Lintels", in Research Reports on Ancient Maya Writing, 23-25, Center for Maya Research, Washington, p. 7-14.

Kupprat Félix A.

2014 "El texto, la imagen y el problema de la narrativa maya en el periodo Clásico", ponencia presentada en el marco de las Primeras Jornadas Académicas 
Algunas reflexiones sobre la representación del tiempo

"Imagen y Escritura en Mesoamérica. Diferencias y relaciones entre ellas", Ciudad de México, Distrito Federal, México, 5 de septiembre de 2014.

LaCadena García-Gallo Alfonso

2009 "Apuntes para un estudio sobre literatura maya antigua", in Antje Gunsenheimer, Tsubasa Okoshi y John F. Chuchiak (eds), Texto y contexto: perspectivas intraculturales en el análisis de la literatura maya yucateca, Shaker Verlag Aachen (Estudios Americanistas de la Universidad de Bonn, 47), Bonn, p. 31-52.

2010 "Gramática maya jeroglífica", in Introducción a la escritura jeroglífica maya, cuaderno de trabajo, talleres de escritura jeroglífica maya, en el marco de la 15 a Conferencia Maya Europea, 30 de noviembre al 2 de diciembre de 2010, Museo de América, Madrid.

Lacadena García-Gallo Alfonso y Søren Wichmann

2004 "On the Representation of the Glottal Stop in Maya Writing", in Søren Wichmann (ed.), The Linguistics of Maya Writing, The University of Utah Press, Salt Lake City, p. 103-162.

s.f. "Harmony Rules and the Suffix Domain: A Study of Maya Scribal Conventions" [on-line], http://email.eva.mpg.de/\%7Ewichmann/harm-rul-suf-dom7.pdf.

LANDA fray Diego de

1864 Relation des choses de Yucatan de Diego de Landa, texte espagnol et traduction française en regard, comprenant les signes du calendrier, etc., d'après les monuments américains, par l'abbé Brasseur de Bourbourg, Imprimeries de $\mathrm{M}^{\mathrm{me}}$ ve Belin (Collection de documents dans les langues indigènes, pour servir à l'étude de l'histoire et de la philologie de l'Amérique ancienne, vol. 3), Saint-Cloud.

López Austin Alfredo

1989 [3 $3^{\mathrm{a}}$ éd.], Cuerpo humano e ideología. Las concepciones de los antiguos nahuas, Universidad Nacional Autónoma de México-Instituto de Investigaciones Antropológicas (Serie Antropológica, 39), México, 2 vols.

2015 "Ecumene Time, Anecume Time: Proposal of a Paradigm", in Anthony F. Aveni (ed.), The Measure and Meaning of Time in Mesoamerica and the Andes, Dumbarton Oaks Research Library and Collection, Washington, p. 29-52.

2016 La cosmovisión de la tradición mesoamericana. Primera parte, Editorial Raíces, (Arqueología Mexicana, Edición Especial 68), México.

LÓPEZ Austin Alfredo y Leonardo LóPEZ LuJÁN

2009 Monte Sagrado. Templo Mayor, Universidad Nacional Autónoma de MéxicoInstituto de Investigaciones Antropológicas, México.

MARTIN Simon

2006 "The Old Man of the Maya Universe: Towards on Understanding of God N", ponencia presentada en The 2006 Maya Meetings, March 17, 2006, Austin.

2015 "The Old Man of the Maya Universe: A Unitary Dimension to Ancient Maya Religion", in Charles Golden, Stephen D. Houston y Joel Sidmore (eds). Maya Archaeology, vol. 3, The Pre-Columbian Art Research Institute, San Francisco, p. 186-227.

Martin Simon y Nikolai Grube

2008 [2a. éd.], Chronicle of the Maya Kings and Queens. Deciphering the Dynasties of the Ancient Maya, Thames and Hudson, Londres. 
Mathews Peter L.

1980 "Notes on the Dynastic Sequence of Bonampak" (part 1), in Merle Greene Robertson (ed.), Third Palenque Round Table, 1978 (part 2), University of Texas Press, Austin/Londres, p. 60-73.

MiLLer Mary Ellen

1986 The Murals of Bonampak, Princeton University Press, Princeton.

Miller Mary Ellen y Claudia BritTenham

201 The Spectacle of the Late Maya Court. Reflections on the Murals of Bonampak, University of Texas Press/Consejo Nacional para la Cultura y las Artes-Instituto Nacional de Antropología e Historia, Austin.

Miller Mary Ellen y Simon Martin

2004 Courtly Art of the Ancient Maya, Thames and Hudson, London and New York. MilLer Mary Ellen y Megan O’NeIL

2014 [2a. ed.] Maya Art and Architecture, Thames and Hudson, Londres.

MONTGOMERY John

2001 Tikal. An Illustrated History of the Ancient Maya Capital, Hippocrene Books, Inc., Nueva York.

Montolíu Villar María

1989 Cuando los dioses despertaron (conceptos cosmológicos de los antiguos mayas de Yucatán estudiados en el Chilam Balam de Chumayel, Universidad Nacional Autónoma de México-Instituto de Investigaciones Antropológicas, México.

Nava Román Rosario

2009 El color negro en la piel y su poder político en el mundo mesoamericano, tesis de maestría en Historia del Arte, Universidad Nacional Autónoma de México-Facultad de Filosofía y Letras-Instituto de Investigaciones EstéticasPosgrado en Historia del Arte, México.

NiELSEN Jesper

2003 Art of the Empire: Teotihuacan Iconography and Style in Early Classic Maya Society (AD 380-500), Ph.D., University of Copenhaguen, The Department of American Indian Languages and Cultures, The Institute of History of Religions, Copenhague, 2 vols.

Pillsbur Joanne, Miriam Doutriaux, Reiko Ishinara-Brito y Alexandre Tokovinine (eds)

2012 Ancient Maya Art at Dumbarton Oaks, Dumbarton Oaks Research Library and Collection (Pre-Columbian Art at Dumbarton Oaks, 4), Washington,.

Proskouriakoff Tatiana A.

1963 "Historical Data in the Inscriptions of Yaxchilán, Part I", Estudios de Cultura Maya, vol. III, p. 149-167.

2002 An Album of Maya Architecture, reimp. de la obra original de 1946, Dover Publications, Inc., Mineola.

QuenOn Michel y Geneviève Le ForT

1997 "Rebirth and Resurrection in Maize God Iconography", in Justin Kerr (ed.), The Maya Vase Book: A Corpus of Rollout Photographs of Maya Vases, vol. 5, Kerr Associates, Nueva York, p. 884-902. 
Algunas reflexiones sobre la representación del tiempo

REENTS-BudET Dorie J.

1994 Painting the Maya Universe: Royal Ceramics of the Classic Period, con contribuciones de J. W. Ball, R. L. Bishop, V. M. Fields y B. MacLeod, Duke University Press, Furham/Londres.

ROBERTSON Merle Greene

1991 The Sculpture of Palenque. IV: The Cross Group, the North Group, the Olvidado, and Other Pieces, Princeton University Press, Princeton.

SAnz GonZÁlez Mariano

2001 “Breve análisis del clítico ch’orti’ -ix. Una aportación al debate epigráfico sobre ‘tiempo-aspecto’ en las inscripciones mayas clásicas”, Mayab, 14, p. 67-70.

SCHELE Linda y Mary Ellen Miller

1986 The Blood of Kings. Dynasty and Ritual in Maya Art, George Braziller, Inc./ Kimbell Art Museum, Nueva York/Fort Worth.

SChUMANN Gávez Otto

1981 “La relación lingüística chuj-tojolabal”, in Mario H. Ruz Sosa (ed.), Los legítimos hombres. Aproximación antropológica al grupo tojolabal, Universidad Nacional Autónoma de México-Instituto de Investigaciones Filológicas-Centro de Estudios Mayas, México, vol. I, p. 129-169.

Sheseña Hernández Alejandro

2010 "Los nombres de los naguales en la escritura jeroglífica maya: religión y lingüística a través de la onomástica”, Journal of Mesoamerican Languages and Linguistics, 2 (1), p. 1-39.

SMITH Mary Elizabeth

1973 Picture of Writing from Ancient Southern Mexico. Mixtec Place Signs and Maps, University of Oklahoma Press (The Civilization of the American Indian Series, vol. 124), Norman.

Sмiтн Robert Eliot

1955 Ceramic Sequence at Uaxactun, Guatemala, University-Middle American Research Institute/Carnegie Institution of Washington (Publication 20), 2 vols, New Orleans.

STONE Andrea J.

1995 Images from the Underworld. Naj Tunich and the Tradition of Maya Cave Painting, University of Texas Press, Austin.

STUART David S.

1994 "Letter from David Stuart to Linda Schele posted on David Stuart's blog", Maya Decipherment [on-line], http://decipherment.files.wordpress.com/2007/09/ itzam-letter-1994.pdf.

1996 "Kings of Stone: A Consideration of Stelae in Ancient Maya Ritual and Representation", Res. Anthropology and Aesthetics, 29/30, p. 148-171.

2000 “The Arrival of Strangers': Teotihuacan and Tollan in Classic Maya History", in David Carrasco, Lindsay Jones y Scott Sessions (eds), Mesoamerica's Classic Heritage from Teotihuacan to the Aztecs, University Press of Colorado, Niwot, p. 465-512.

2003 "La ideología del sacrificio entre los mayas", Arqueología Mexicana, 6 (63), p. 24-29. 
StUART David S.

2005 "A Foreign Past. The Writing and Representation of History on a Royal Ancestral Shrine at Copan”, in E. Wyllys Andrews y William L. Fash (eds), Copán. The History of an Ancient Maya Kingdom, School of American Research Press/James Currey, Santa Fe/Oxford, p. 373-394.

2006 "The Palenque Mythology. Materials to accompany presentations by David Stuart, Peter Mathews, Alfonso Morales, Erik Velásquez García and Guillermo Bernal Romero", in Sourcebook for the 30th Maya Meetings. The University of Texas at Austin-Department of Art and Art History-The Mesoamerican Center, Austin, p. 85-194.

2008 "Copan Archaeology and History New Finds and New Research. Sourcebook for the $32^{\text {nd }}$ Maya Meetings. February 25-March 2, 2008", The University of Texas at Austin-Department of Art and Art History-The Mesoamerican Center, Austin.

2011 The Order of Days. Unlocking the Secrets of the Ancient Maya, Three Rivers Press, Nueva York.

2013 “Tonina's Curious Ballgame”, Maya Decipherment. Ideas on Ancient Maya Writing and Iconography [on-line], https://decipherment.wordpress. com/2013/06/11/report-toninas-curious-ballgame/.

2014 "A Possible Sign for Metate", in Maya Decipherment. Ideas on Ancient Maya Writing and Iconography [on-line], https://decipherment.wordpress.com/?s=metate.

Stuart David S. y Stephen D. Houston

1994 Classic Maya Place Names, Dumbarton Oaks Research Library and Collection, Washington.

Stuart David S. y George E. STuart

2008 Palenque. Eternal City of the Maya, Thames and Hudson, Londres.

1993 Los reinos perdidos de los mayas, National Geographic Society/División de Libros, Washington.

TAuBe Karl A.

1983 “The Classic Maya Maize God: A Reappraisal”, in Merle Greene Robertson y Virginia Fields (ed.), Fifth Palenque Round Table, 1983, The Pre-Columbian Art Research Institute, San Francisco, p. 171-181.

2009 "The Maya Maize God and the Mythic Origins of Dance", in Geneviève Le Fort, Raphaël Gardiol, Sebastian Matteo y Christophe Helmke (eds), The Maya and their Sacred Narratives: Text and Context of Maya Mythologies. 12th European Maya Conference. Geneva, December 2007, Verlag Anton Sauwrein, Markt Schwaben (Acta Mesoamericana, vol. 20), p. 41-52.

ToKovinine Alex

2012 "Writing Color. Words and Images of Colors in Classic Maya Insciptions", Res. Anthropology and Aesthetics, vol. 61/62, primavera/otoño, p. 283-299.

VAIL Gabrielle y Christine HERNÁNDEZ

2013 Re-Creating Primordial Time. Fundation Rituals and Mythology in the Postclassic Maya Codices, University Press of Colorado, Boulder. 
Algunas reflexiones sobre la representación del tiempo

VelÁSQUEZ García Erik

2004 “Los escalones jeroglíficos de Dzibanché”, in Enrique Nalda Hernández (ed.), Los cautivos de Dzibanché, Consejo Nacional para la Cultura y las ArtesInstituto Nacional de Antropología e Historia, México, p. 79-103.

2007 "La máscara de 'rayos X'. Historia de un artilugio iconográfico en el arte maya”, Anales del Instituto de Investigaciones Estéticas, 90, p. 7-36.

2009a “Imagen, texto y contexto ceremonial del 'Ritual de los Ángeles': viejos problemas y nuevas respuestas sobre la narrativa sagrada en los libros de Chilam Balam", in Geneviève Le Fort, Raphaël Gardiol, Sebastian Matteo y Christophe Helmke (eds), The Maya and their Sacred Narratives: Text and Context of Maya Mythologies. 12th European Maya Conference. Geneva, December 2007, Verlag Anton Sauwrein, Markt Schwaben (Acta Mesoamericana, 20), p. 55-74.

2009b Los vasos de la entidad política de 'Ik': una aproximación histórico-artística. Estudio sobre las entidades anímicas y el lenguaje gestual y corporal en el arte maya clásico, tesis de doctorado en Historia del Arte, Universidad Nacional Autónoma de México-Facultad de Filosofía y Letras-Instituto de Investigaciones Estéticas-Posgrado en Historia del Arte, México.

2009c "Reflections on the Codex Style and the Princeton Vessel", The PARI Journal, 10 (1), p. 1-16.

2010 "Los Dioses Remeros mayas y sus posibles contrapartes nahuas", in Laura van Broekhoven, Rogelio Valencia Rivera, Benjamin Vis y Frauke Sachse (eds), The Maya and their Neighbours. Internal and External Contacts Through Time. Proceedings of the 10th European Maya Conference. Leiden, December 9-10, 2005, Verlag Anton Sauwrein, Markt Schwaben (Acta Mesoamericana, 22), p. 115-131.

2011a “Gobernantes simultáneos en el señorío de Ik': evidencia epigráfica de un atípico sistema de organización política en la región del lago Petén Itzá", in Bárbara Arroyo López, Lorena Paiz Aragón, Adriana Linares Palma y Ana Lucía Arroyave Prera (eds), XXIV Simposio de Investigaciones Arqueológicas en Guatemala. Museo Nacional de Arqueología y Etnología, 2010, Ministerio de Cultura y Deportes-Instituto de Antropología e Historia/Asociación Tikal, Guatemala, p. 973-987.

2011b "La Casa de la Raíz del Linaje y el origen sagrado de las dinastías mayas", in Peter Krieger (ed.), La imagen sagrada y sacralizada. XXVIII Coloquio Internacional de Historia del Arte, Universidad Nacional Autónoma de México-Instituto de Investigaciones Estéticas, México, vol. 2, p. 407-434.

2015a "El juego de pelota entre los mayas del periodo Clásico (250-900 d.C.). Algunas reflexiones", in María Teresa Uriarte Castañeda (ed.), El juego de pelota mesoamericano. Temas eternos, nuevas aproximaciones, Universidad Nacional Autónoma de México-Instituto de Investigaciones Estéticas-Dirección General de Publicaciones y Fomento Editorial, p. 251-326.

2015b [2a ed,] "Las entidades y las fuerzas anímicas en la cosmovisión maya clásica", in Alejandra Martínez de Velasco Cortina y María Elena Vega Villalobos (eds), Los mayas: voces de piedra, Turner/Editorial Ámbar Diseño/Universidad Nacional Autónoma de México-Dirección General de Publicaciones, Madrid, p. 177-195. 


\section{VelÁSQUEZ García Erik}

s.f.a Morada de dioses: los componentes anímicos del cuerpo humano entre los mayas clásicos, México, Secretaría de Cultura, Fondo de Cultura Económica (Sección de Obras de Antropología). Este libro se publicará en 2018.

s.f.b "Reflexiones sobre el tiempo histórico en las inscripciones mayas", ponencia presentada en el marco de la VII Mesa Redonda de Palenque. Los mayas y las concepciones del tiempo, Palenque, Chiapas, México, 29 de noviembre de 2011.

Wichmann Søren

2004 "The Names of Some Major Classic Maya Gods", in Daniel Graña Behrens, Nikolai Grube, Christian M. Prager, Frauke Sachse, Stefanie Teufel y Elisabeth Wagner (eds), Continuity and Change-Mayan Religious Practices in Temporal Perspective. 5th European Maya Conference, University of Bonn, December 2000, Verlag Anton Saurwein, Markt Schwaben (Acta Mesoamericana, vol. 14), p. 77-86.

WRIGHT Terence

2011 Manual de fotografía, traducción al español de Miguel Ángel González Lara, Akal Ediciones, Madrid.

YADEUn Angulo Juan

1992 Toniná: el laberinto del inframundo, Gobierno del estado de Chiapas, Tuxtla Gutiérrez.

ZENDER Marc Uwe

1999 Diacritical Marks and Underspelling in the Classic Maya Script. Implications for the Decipherment, tesis de maestría, University of Calgary-Faculty of Graduate Studies-Department of Archaeology, Calgary. 